Esta revista forma parte del acervo de la Biblioteca Jurídica Virtual del Instituto de Investigaciones Jurídicas de la UNAM

\title{
Empresas, derechos humanos y el régimen internacional del cambio climático: la configuración de las obligaciones climáticas para las empresas
}

\section{Businesses, Human Rights and the International Climate Change Regime: The Emergence of Climate Obligations for Corporations}

\section{Les entreprises, les droits de l'homme et le régime international du changement climatique: l'émergence d'obligations climatiques pour les entreprises}

\section{Daniel Iglesias Márquez}

SUMARIO: I. Introducción. II. Los actores no estatales en el régimen internacional del cambio climático: especial referencia a las empresas. III. ¿Hacia la configuración de obligaciones climáticas para las empresas? IV. Conclusiones.

V. Bibliografía.

* Investigador postdoctoral "Juan de la Cierva" de derecho internacional público y relaciones internacionales de la Universidad de Sevilla, email: dimarquez@us.es. El presente estudio ha sido realizado en el marco del proyecto de investigación "Gobernanza y aplicación de la responsabilidad social empresarial en la Unión Europea” (DER2017-85834-R).

Artículo recibido el 11 de marzo de 2019 Aprobado para publicación el 3 de octubre de 2019 
RESUMEN: La presente investigación analiza la interrelación entre el cambio climático, las empresas y los derechos humanos. Esto, con el objetivo de discernir las obligaciones climáticas de las empresas que, consideramos, deberían estar incluidas en el régimen internacional del cambio climático con el fin de que, junto con los Estados, compartan los compromisos vinculantes de reducción de emisiones de gases de efecto invernadero y aseguren las condiciones necesarias para el disfrute de los derechos humanos a través de la implementación de procesos efectivos e integrales de diligencia debida. Para ello, se analizan algunos instrumentos internacionales de soft law que contienen o clarifican estándares climáticos aplicables a las operaciones de las empresas o reconocen el papel de las empresas en la lucha contra el cambio climático.

Palabras clave: cambio climático, actores no estatales, empresas y derechos humanos, soft law, obligaciones climáticas.

ABSTRACT: This paper analyses the interrelation between climate change, businesses and human rights. The main objective is to discern the climate obligations of corporations, which should be included in the international climate change regime in order to share binding greenhouse gas emission reduction targets with States and ensure the necessary conditions for the enjoyment of human rights through the implementation of effective and comprehensive due diligence processes. To this end, the paper examines some soft law instruments that contain or clarify climate standards applicable to business activities or recognize the role of corporations in addressing climate change.

Key words: climate change, non-state actors, business and human rights, soft law, climate obligations.

RÉSUMÉ: Cet article analyse l'interrelation entre le changement climatique, les entreprises et les droits de l'homme. L'objectif principal est de déterminer les obligations des entreprises en matière de climat, qui devraient être incluses dans le régime international de lutte contre le changement climatique afin de partager, avec les États, des engagements contraignants en matière de réduction des émissions et de garantir les conditions nécessaires à la jouissance des droits de l'homme dans la mise en ouvre de processus efficaces de diligence raisonnable. À cette fin, le document examine certains instruments du soft law qui contiennent ou clarifient les normes climatiques applicables aux activités commerciales ou reconnaissent le rôle des entreprises dans la lutte contre le changement climatique.

Mots-clés: changement climatique, acteurs non étatiques, entreprises et droits humains, soft law, obligations climatiques. 


\section{INTRODUCCIÓN}

A partir de la Revolución Industrial, las emisiones de gases de efecto invernadero (GEI) comenzaron a aumentar exponencialmente. En 2010, las emisiones de GEI provenientes de las actividades industriales se habían duplicado en comparación con $1970 .{ }^{1}$ Esto se debió, principalmente, a los procesos de transformación de los recursos naturales (carbón, gas, petróleo, biomasa, etcétera) en energía. El dióxido de carbono $\left(\mathrm{CO}_{2}\right)$ generado en las actividades de las empresas energéticas y de transporte, altamente dependientes de la quema de combustibles fósiles, ${ }^{2}$ y otros gases contaminantes, como el metano y los óxidos de nitrógeno, constituyen las principales emisiones provenientes de las industrias. ${ }^{3}$

Los estudios de Richard Heede mapean las emisiones acumuladas de las mayores empresas emisoras de GEI y concluyen que su contribución histórica al cambio climático es de $71 \%$ de las emisiones globales de GEI industriales desde 1988. ${ }^{4}$ Este grupo de casi 100 empresas, conocidas como Carbon Majors, lo conforman tanto empresas privadas como estatales productoras de crudo o gas natural, de carbón y de cemento. Entre éstas, se encuentran: ExxonMobil, Shell, Pemex, Peabody, BHP Billiton, Petrobras, Total y Lukoil. Las investigaciones científicas, como las de Heede, permiten, por tanto, identificar a los principales actores que aceleran el calentamiento

1 Véase, IPCC, "Summary for Policymakers", en IPCC, Global warming of $1.5^{\circ} \mathrm{C}$. An IPCC Special Report on the impacts of global warming of $1.5^{\circ} \mathrm{C}$ above pre-industrial levels and related global greenhouse gas emission pathways, in the context of strengthening the global response to the threat of climate change, sustainable development, and efforts to eradicate poverty, Ginebra, World Meteorological Organization, 2018, p. 36.

2 Ferrey, Steven, "Corporate social responsibility and climate change", en Farber, Daniel A. y Peeters, Marjan (eds.), Climate Change Law, vol. I, Cheltenham-Massachussetts, Edwar Elgar, 2016, pp. 68-79.

3 IPCC, Climate Change 2007: Mitigation. Contribution of Working Group III to the Fourth Assessment Report of the Intergovernmental Panel on Climate Change, Cambridge, Nueva York, Cambridge University Press, 2007, p. 449.

4 Heede, Richard, "Tracing Anthropogenic Carbon Dioxide and Methane Emissions to Fossil Fuel and Cement Producers, 1854-2010”, Climatic Change, 2013, vol. 122, núm. 1-2, pp. 229-241; Griffin, Paul, The Carbon Majors Database. CDP Carbon Majors Report 2017, Londres, CPD UK, 2017, p. 8. 
global y que, a su vez, se benefician de ello sin internalizar los costos ambientales de sus operaciones.

Debido a los impactos climáticos a los que contribuyen, los Carbon Majors se han convertido en el objeto de diversas estrategias de litigo para que asuman los costes de prevención y adaptación, así como para hacer efectiva su responsabilidad por los daños causados por sus respectivas contribuciones al cambio climático. ${ }^{5}$ En la primera década de los años 2000, se registraron en los Estados Unidos de América algunas de las primeras demandas de tortlaw en contra de ciertas empresas del sector extractivo y energético. Por ejemplo, en 2005, un grupo de personas afectadas por el huracán Katrina interpuso una demanda colectiva en contra de las principales empresas emisoras de GEI en los Estados Unidos. ${ }^{6}$ Los demandantes reclamaban una indemnización por los daños y perjuicios causados por el huracán. Según los demandantes, este fenómeno fue más intenso debido al calentamiento global, al que contribuyen directamente dichas empresas.

Desde entonces, estas acciones asociadas a los impactos del cambio climático en contra de las empresas se han expandido no sólo a otras instancias judiciales y no judiciales, sino también a otras jurisdicciones más allá de los EUA. ${ }^{7}$ En este contexto han comenzado a surgir litigios climáticos estratégicos en los que la parte actora alega que la contribución de las empresas al cambio climático vulnera el disfrute de los derechos humanos. ${ }^{8}$ Por ejemplo, en 2015, Greenpeace Southeast Asia, junto con ciudadanos filipinos afectados por diversos eventos climáticos extremos, interpusieron una petición ante la Comisión de Derechos Humanos de Filipinas, con el fin de solicitar el ejercicio de sus competencias para investigar la responsabilidad

Iglesias Márquez, Daniel y Felipe Pérez, Beatriz, “Anhelando justicia en la era del cambio climático: de la teoría a la práctica”, Revista Catalana de Derecho Ambiental, 2018, vol. 9, núm. 2, pp. 1-14.

6 Comer vs. Murphy Oil USA Inc 607 F.3d 1049 (5th Cir 2010).

7 En la práctica de la litigación climática, las empresas son el segundo tipo de demandados más comunes en estos casos. La base de datos del Sabine Centre registra al menos 40 litigios climáticos en contra de empresas en diversas jurisdicciones, como la de Estados Unidos, Australia, Alemania, Canadá y Filipinas, entre otros. Para consultar la base de datos sobre litigios climáticos en los Estados Unidos y en otras jurisdicciones del Sabine Centre, véase http:// climatecasechart.com/, consultado el 01 de octubre de 2019.

8 Iglesias Márquez, Daniel, "La responsabilidad de las empresas de respetar los derechos humanos en el contexto de la crisis climática”, Revista de Direito Internacional, 2019, pp. 1-31 (en prensa). 
de las principales empresas emisoras de GEI (Carbon Majors) por su contribución a la vulneración de derechos humanos, como el derecho a la vida, a la salud física y mental, a la alimentación y al agua, entre otros, a causa de los impactos del cambio climático. ${ }^{9}$

En el ámbito europeo, en abril de 2019, el grupo ambientalista Milieu defensie / Friends of the Earth Netherlands, junto con otras organizaciones de la sociedad civil (Action Aid NL, Both ENDS, Fossielvrij NL, Greenpeace NL, Young Friends of the Earth NL y Waddenvereniging) y más de mil ciudadanos, interpusieron una demanda en contra de la empresa Shell ante los tribunales de los Países Bajos. Los demandantes alegan que, debido a las contribuciones de la empresa al cambio climático, ésta incumple su deber de cuidado (duty of care), contemplado en la legislación holandesa, y su responsabilidad de respetar los derechos humanos. Según los demandantes, sobre la base del Acuerdo de París y la evidencia científica que demuestra los riesgos que implica el cambio climático, la empresa tiene el deber de adoptar las medidas necesarias para reducir sus emisiones de GEI. Esto con el fin de prevenir un peligro inminente y real de generar daños que afecten los derechos a la vida privada y familiar, contenidos en el Convenio Europeo de Derechos Humanos (CEDH) (artículos 2o. y 8o.). Por tanto, el objetivo de la demanda es que el tribunal se pronuncie sobre la obligación de Shell de reducir sus emisiones de $\mathrm{CO}_{2}$ en un 45\% en 2030 en comparación con los niveles de 2010 y a cero emisiones netas en 2050, de conformidad con los objetivos del Acuerdo de París. ${ }^{10}$

A la luz de lo anterior, se puede afirmar que la litigación climática se ha convertido en una estrategia para asegurar que los actores estatales y no estatales alcancen los objetivos y compromisos asumidos en el régimen internacional del cambio climático. ${ }^{11}$ En algunos casos, se ha logrado determinar

9 Philippines Reconstruction Movement and Greenpeace vs. Carbon Majors Case No CHRNI-2016-0001 (2015). A la fecha de escritura del presente artículo, la investigación de la Comisión de Derechos Humanos de Filipinas se encuentra en fase final.

10 Milieudefensie et al. vs. Royal Dutch Shell plc, disponible en: http://climatecasechart. com/non-us-case/milieudefensie-et-al-v-royal-dutch-shell-plc/ (consultado el 1o. de octubre de 2019). A la fecha de escritura del artículo, el presente caso se encuentra en fase inicial del proceso.

11 Dellinger, Myanna, "See You in Court: Around the World in Eight Climate Change Lawsuits”, William \& Mary Environmental Law and Policy Review, vol. 42, núm. 2, 2018, pp. 525-551. En los Estados Unidos el litigio climático ha servido para generar cambios en la regulación energética, ya que la mayoría de los casos se enfocan en emisiones del transporte o de las 
que los Estados deben adoptar compromisos de reducción más ambiciosos. Por ejemplo, en los Países Bajos, en 2013, la ONG Urgenda interpuso una acción en contra del Ministerio de Infraestructuras y Medio Ambiente (Ministerie van Infrastructuur en Milieu), exigiendo al Estado que mejorara su meta de reducción de GEI, con el fin de que en 2020 se redujera la cantidad de emisiones de $\mathrm{CO}$, respecto a 1990 en $40 \%$ o, al menos, en 25\%. En 2015, en una decisión pionera, el Tribunal del Distrito de La Haya determinó que el gobierno de los Países Bajos era responsable de asegurar la reducción de las emisiones de $\mathrm{CO}_{2}$ en al menos 25\% para 2020, en lugar del 16\% previsto en su política ambiental. ${ }^{12}$ En 2018, el Tribunal de Apelación confirmó esta decisión y mantuvo el objetivo más ambicioso de reducción de emisiones. ${ }^{13}$ De hecho, los demandantes en el caso en contra de la empresa Shell en los Países Bajos se basan en la experiencia de esta decisión emblemática para presionar a la empresa a que adopte objetivos de reducción más exigentes y una política empresarial alineada con el Acuerdo de París.

Por tanto, la litigación climática en contra de las empresas se mantiene al alza a nivel global. ${ }^{14}$ Esto, junto con la evidencia científica que demuestra su contribución histórica al cambio climático, indica que las empresas deben asumir un papel más activo en la gobernanza climática global. Sin embargo, el régimen internacional del cambio climático no contempla obligaciones ni compromisos directos para las empresas, lo que les permite evadir su responsabilidad de adoptar acciones climáticas que cumplan con el objetivo de mantener el aumento de la temperatura media mundial por debajo de

plantas generadoras de energía. En la medida en que estas acciones legales han aumentado juegan un papel importante en la manera como tienen lugar acciones regulatorias a escalas más pequeñas. Así lo señala Osofsky, Hari M., "The Role of Climate Change Litigation in Establishing the Scale of Energy Regulation", Annals of the Association of American Geographers, vol. 101, núm. 4, 2011, pp. 775-782.

12 Rodríguez García, Noel, "Responsabilidad del Estado y cambio climático: el caso Urgenda contra Países Bajos”, Revista Catalana de Derecho Ambiental, 2016, vol. 7, núm. 2, pp. $1-38$.

13 Verschuuren, Jonathan, "The State of the Netherlands vs. Urgenda Foundation: The Hague Court of Appeal upholds judgment requiring the Netherlands to further reduce its greenhouse gas emissions", Review of European, Comparative and International Environmental Law, vol. 28, núm. 1, 2019, pp. 94-98.

14 Iglesias Márquez, Daniel, "La litigación climática en contra de los Carbon Majors en los Estados de origen: apuntes desde la perspectiva de empresas y derechos humanos”, Revista Electrónica de Estudios Internacionales, núm. 37, 2019, pp. 1-37. 
$2{ }^{\circ} \mathrm{C}$ con respecto a los niveles preindustriales, y así seguir generando beneficios de la crisis climática.

Si bien algunas empresas han apoyado públicamente el Acuerdo de París, pocas han establecido políticas, objetivos o modelos eficaces de reducción de emisiones compatibles con dicho instrumento internacional. Estas acciones climáticas se rigen, a menudo, por cuestiones de competitividad y, por ende, su eficacia e implementación dependen de la existencia de un balance entre la reducción de emisiones y el crecimiento económico de las empresas. Mientras tanto, otras empresas con contribuciones relevantes de GEI siguen tergiversando y desacreditando la ciencia del cambio climático, ${ }^{15}$ así como obstaculizando las políticas y acciones climáticas y de transición energética a nivel nacional e internacional.

El presente artículo responde a la pregunta de investigación sobre cuáles son las obligaciones climáticas de las empresas asociadas a su responsabilidad de respetar los derechos humanos. En particular, se analizan las obligaciones de reducción y de diligencia debida que incluyen la identificación, prevención, mitigación y rendición de cuentas de las emisiones de GEI provenientes de sus actividades, productos y servicios, así como de sus cadenas de suministro. Se examina, por tanto, en qué medida las empresas contribuyen a alcanzar los objetivos establecidos en el régimen internacional del cambio climático.

En primer lugar, se aborda el papel de los actores no estatales en el marco del régimen internacional del cambio climático, con especial referencia a las empresas para identificar la función que han tenido hasta ahora en la gobernanza climática global. En segundo lugar, se analizan las oportunidades que presenta el consenso global de la relación entre el cambio climático y los derechos humanos para fomentar que las empresas adopten acciones

15 La Union of Concerned Scientists (UCS) ha realizado un estudio comparativo de las acciones climáticas de ocho empresas: Arch Coal, BP, Chevron, Conoco Phillips, CONSOL Energy, ExxonMobil, Peabody Energy y Royal Dutch Shell, principalmente se analizan acciones de planeación, divulgación de información y apoyo a políticas climáticas. Los resultados de la UCS son que "[n]one of these companies have demonstrated a level of ambition consistent with keeping global temperature rise within the Paris climate agreement limits that some of them claim to support, many downplay or misrepresent climate science, and all continue to spread climate disinformation through trade and industry groups", "The 2018 Climate Accountability Scorecard Insufficient Progress from Major Fossil Fuel Companies", Union of Concerned Scientists, 2018, disponible en: www.ucsusa.org/climate-accountability-scorecard-2018\#.XAQUJ4tKhpg (consultado el 1o. de octubre de 2019). 
climáticas más ambiciosas y efectivas. Se reflexiona, por tanto, en qué medida la responsabilidad de las empresas de respetar los derechos humanos se extiende a la lucha contra el cambio climático. Para ello, se exploran instrumentos internacionales de soft law aplicables a las actividades de las empresas que identifican y clarifican las obligaciones y medidas climáticas que deben adoptar para contribuir a los objetivos del Acuerdo de París desde una perspectiva de los derechos humanos. Finalmente, se concluye con una reflexión sobre la necesidad de explorar las fronteras del derecho internacional que, en su statu quo, ha sido insuficiente para responder de manera efectiva a las crisis sociales y ambientales en la era del Antropoceno.

\section{LOS ACTORES NO ESTATALES EN EL RÉGIMEN INTERNACIONAL DEL CAMBIO CLIMÁTICO: ESPECIAL REFERENCIA A LAS EMPRESAS}

En 1988, la comunidad internacional hacía un llamado a los actores no estatales a reducir sus emisiones de GEI y a realizar una transición energética a través de las inversiones en energías sostenibles y la reducción del consumo de combustibles fósiles. La Conferencia Mundial sobre la Atmósfera Cambiante, convocada por la Organización Meteorológica Mundial, marcaba una hoja de ruta para que el sector industrial, junto con otros actores estatales y no estatales, adoptaran acciones específicas para prevenir la crisis inminente causada por la contaminación de la atmósfera y, a su vez, apoyaran el trabajo del Grupo Intergubernamental de Expertos sobre Cambio Climático (IPCC, por sus siglas en inglés) que se había creado ese mismo año. Se sugería entonces que la lucha contra el cambio climático requería no sólo la acción de los Estados, sino también de otros agentes que son parte del problema y de la solución, ya que "[n]o country can tackle this problem in isolation". ${ }^{16}$

La evidencia científica de los años ochenta que demostraba que, el aumento de las emisiones de carácter antropogénico incrementa las concentraciones de GEI y sus consecuencias ambientales, económicas y sociales,

16 Véase, "The Changing Atmosphere: Implications for Global Security. Conference Statement”, disponible en: http://cmosarchives.ca/History/ChangingAtmosphere1988e.pdf (consultado el 1o. de octubre de 2019). 
fue el detonante para que la comunidad internacional comenzara a asumir el compromiso de luchar contra el cambio climático y sus impactos negativos. El debate científico poco a poco se trasladó a la arena política, lo que favoreció que, a inicios de los noventa, en el marco de la Conferencia de las Naciones Unidas sobre el Medio Ambiente y el Desarrollo, celebrada en Río de Janeiro en 1992, se adoptara la Convención Marco de las Naciones Unidas sobre el Cambio Climático (CMNUCC). ${ }^{17}$ Esta Convención establecía el compromiso de los Estados de estabilizar las concentraciones de los GEI en la atmósfera a un nivel que impidiera cualquier perturbación humana peligrosa del sistema climático (artículo 2o.).

Sobre la base de los compromisos de mitigación y adaptación asumidos en la CMNUCC, en 1997 se adoptó el primer acuerdo vinculante a nivel internacional para la reducción de emisiones, el Protocolo de Kioto. ${ }^{18}$ Este instrumento vinculante, que no entró en vigor sino hasta 2005, establecía en su anexo 1 compromisos cuantificados de limitación y reducción de las emisiones en un 5\% de media entre 2008 y 2012 para los países industrializados, tomando como referencia los niveles de 1990. Asimismo, incluía herramientas para abaratar los costos de mitigación de seis tipos de gases que producen el efecto invernadero. Para ello, se crearon tres mecanismos flexibles: Aplicación Conjunta (AC), Mecanismo de Desarrollo Limpio (MDL) y Comercio de Emisiones de Carbono (CEC). No obstante, estos mecanismos han estado sujetos a fuerte críticas ya que en lugar de reducir las emisiones en el origen permiten que las empresas, así como las entidades bancarias y financieras internacionales, gobiernos y particulares, financien proyectos de ahorro de emisiones fuera del territorio donde se deberían reducir y que, a menudo, vulneran los derechos humanos de

17 La CMNUCC entró en vigor en 1994 y ha sido ratificado por 197 Estados y por la Unión Europea. ONU, Convención Marco de las Naciones Unidas sobre el Cambio Climático. Serie de Tratados de las Naciones Unidas, Nueva York, 1992, vol. 1771, p. 107, disponible en: https://treaties.un.org/pages/ViewDetailsIII.aspx?src=TREATY\&mtdsg_no $=$ XXVII$7 \&$ chapter $=27 \&$ Temp $=m t d s g 3 \&$ clang $=\_e n($ consultado el 1 o. de octubre de 2019).

18 El Protocolo de Kioto ha sido ratificado por 191 Estados y la Unión Europea, ONU, Protocolo de Kioto a la Convención Marco de las Naciones Unidas sobre Cambio Climático. Serie de Tratados de las Naciones Unidas, 1997, vol. 2303, disponible en: https://treaties.un.org/pages $/$ ViewDetails.aspx?src $=$ TREATY\&mtdsg_no $=X X V I I-7$-a\&chapter $=27 \&$ clang $=\_$en (consultado el 1o. de octubre de 2019). 
las comunidades locales. ${ }^{19}$ Las compensaciones han servido para garantizar nuevos fondos a algunos de los sectores industriales más contaminantes del sur global y para ofrecer a las empresas y los gobiernos del norte global una salida con el fin de evitar un cambio de paradigma efectivo en sus propios sistemas energéticos y prácticas industriales.

A pesar de lo anterior, la CMNUCC y el Protocolo de Kioto marcaron un hito relevante en el desarrollo del régimen internacional del cambio climático. En 2007, en el seno de la CMNUCC se daba inicio en Bali a un largo proceso de negociaciones para lograr un acuerdo vinculante que sustituyera al Protocolo de Kioto, que concluyó en diciembre de 2015, con la adopción por consenso del Acuerdo de París. ${ }^{20}$ Este instrumento, que aporta novedades al derecho internacional contemporáneo, establece un nuevo objetivo de mantener el aumento de la temperatura media mundial muy por debajo de $2{ }^{\circ} \mathrm{C}$ con respecto a los niveles preindustriales, y proseguir los esfuerzos para limitar ese aumento de la temperatura a $1.5^{\circ} \mathrm{C}$ (artículo 2o.).

La adopción del Acuerdo de París se enmarca en un contexto global diferente al de la década de los noventa, en el que los discursos que negaban el cambio climático pierden fuerza, y se requieren urgentemente de acciones climáticas más ambiciosas, que implican la participación de las autoridades nacionales y subnacionales, la sociedad civil y el sector privado, incluidas las empresas, con el fin de reducir la elevación del nivel del mar, evitar una mayor extinción de especies y limitar otros efectos adversos del cambio climático. ${ }^{21}$ Asimismo, la adopción del Acuerdo de París tiene lugar en un escenario en el que los avances científicos han permitido identificar y cuantificar la contribución de las empresas al cambio climático, así como

19 Olawuyi señala la falta de consulta y participación de las comunidades en la planeación e implementación de los MDL. Por tanto, incide en la necesidad de instituciones y mecanismos para integrar estándares de derechos humanos en los proyectos y acciones de las empresas destinados a combatir el cambio climático. Olawuyi, Damilola S., "Climate Justice and Corporate Responsibility: Taking Human Rights Seriously in Climate Actions and Projects”, Journal of Energy \& Natural Resources Law, vol. 34, núm. 1, 2016, pp. 27-44.

20 El Acuerdo de París entró en vigor en noviembre de 2016 y ha sido ratificado por 185 Estados de la CMNUCC. Véase, Informe de la Conferencia de las Partes, 21 periodo de sesiones. París, 30 de noviembre a 11 de diciembre de 2015. Doc. FCCC/CP/2015/L.9, disponible en: https://unfccc.int/resource/docs/2015/cop21/spa/109r01s.pdf (consultado el 1o. de octubre de 2019).

21 IPCC, Summary for Policymakers..., cit. 
atribuir con mayor grado de certeza determinados eventos climáticos a las emisiones de GEI de las empresas o de otros emisores relevantes. ${ }^{22}$

A pesar de la creciente evidencia científica, el Acuerdo de París no incluye obligaciones directas o compromisos vinculantes de reducción de emisiones para los actores privados, como las empresas o determinados sectores industriales. Los instrumentos del régimen internacional del cambio climático mantienen la visión clásica del derecho internacional (statecentered approach) y, por tanto, se enfocan en la distribución de obligaciones climáticas entre los Estados. Así, la CMNUCC y el Protocolo de Kioto concentran la responsabilidad de la lucha contra el cambio climático en los países industrializados, que son los Estados obligados a adoptar las medidas de mitigación, limitando las emisiones de GEI y disminuyendo la huella de carbono. En este sentido, era de suponerse que los compromisos climáticos de las empresas, operando en los países que no pertenecen al Anexo I de la Convención fueran mucho más laxos, en comparación con los de las que operaban en los países obligados a cumplir objetivos concretos de reducción de emisiones. ${ }^{23}$

A diferencia de los instrumentos anteriores, el Acuerdo de París marca un punto de inflexión, ya que sus disposiciones — con distinta intensidad normativa - vinculan por igual a todos los Estados parte, tanto a los países desarrollados como en desarrollo. Sin embargo, la flexibilidad de este instrumento permite a los Estados modular sus compromisos individuales a través de las contribuciones determinadas a nivel nacional (NDC, por sus siglas en inglés), que se ajustan a las circunstancias particulares de cada uno de ellos y al estado del conocimiento científico, así como formular sus planes para la aplicación y cumplimiento de sus obligaciones en el ámbito nacional. La laxitud de este instrumento plantea varias dudas sobre el carácter normativo de sus disposiciones. ${ }^{24}$

22 Véase Ekwurzel, Brenda et al., "The Rise in Global Atmospheric $\mathrm{CO}_{2}$, Surface Temperature, and Sea Level from Emissions Traced to Major Carbon Producers", Climatic Change, 2017, vol. 144, núm. 4, pp. 579-590.

23 Nasiritousi, Naghmeh, "Fossil Fuel Emitters and Climate Change: Unpacking the Governance Activities of Large Oil and Gas Companies”, Environmental Politics, vol. 26, núm. 4, 2017, pp. 624-647.

24 Nava Escudero, César, "El Acuerdo de París. Predominio del soft law en el régimen climático”, Boletín Mexicano de Derecho Comparado, vol. 49, núm. 147, 2016, pp. 99-135. 
El régimen internacional del cambio climático hace evidente la dificultad del derecho internacional en su estado actual para abordar un problema global en el que están implicados diversos actores estatales y no estatales, así como, a su vez, la necesidad de explorar sus fronteras para articular soluciones efectivas. A pesar de algunos desarrollos positivos en este régimen, la voluntad política de los Estados ha sido hasta ahora insuficiente a la hora de alinear los intereses nacionales con los esfuerzos globales que premitan hacer frente al cambio climático y a sus impactos negativos. Así, países como Estados Unidos nunca ratificaron el Protocolo de Kioto y Canadá prefirió retirarse antes de asumir los compromisos de reducción de emisiones en el segundo periodo. En este sentido, la decisión del presidente Trump de abandonar el Acuerdo de París afecta al futuro, la naturaleza jurídica y la eficacia de este instrumento. La retirada de Estados Unidos, uno de los países donde están domiciliadas o tienen su sede un gran número de las empresas de los Carbon Majors, desmantela en gran medida los progresos alcanzados a nivel internacional en materia de cambio climático. ${ }^{25}$

Por otra parte, el vacío de los instrumentos internacionales del cambio climático en relación con el papel activo y los compromisos climáticos que deberían adoptar los agentes no estatales, como las empresas, obvia la contribución considerable e histórica de los agentes económicos no estatales al cambio climático a través de las emisiones de GEI derivadas de sus actividades. Asimismo, deja un margen considerable en el ámbito de las relaciones internacionales para que obstaculicen y suavicen las políticas y acciones climáticas y de transición energética, a nivel nacional e internacional, en beneficio propio. ${ }^{26}$

25 Fajardo, Teresa, "El Acuerdo de París sobre el cambio climático: sus aportaciones al desarrollo progresivo del derecho internacional y las consecuencias de la retirada de los Estados Unidos”, Revista Española de Derecho Internacional, vol. 70, núm. 1, 2018, pp. 23-51.

26 Sobre cómo las empresas y sectores industriales afectan y obstaculizan el desarrollo de las políticas y acciones climáticas globales, véase Corporate Accountability International, Inside Job: Big Polluters' lobbyists on the inside at the UNFCCC, Boston, 2017. Durante la COP 21, empresas de combustibles fósiles fueron patrocinadores oficiales. En este sentido, las ONG han manifestado que las empresas deben desvincularse de las cumbres del clima, de la misma forma que se dio en el marco de la Organización Mundial de la Salud (OMS). La OMS se dio cuenta de que nunca iba a ser capaz de atajar el consumo de tabaco con eficacia si tenía que negociar para ello con el lobby de las industrias, algo incompatible con los intereses de la salud pública. Véase, Sabido, Pascoe, Receta para el cambio climático. La influencia de las empresas 
Las negociaciones climáticas en el seno de las Naciones Unidas han estado influenciadas en gran medida por los intereses de las grandes empresas que han participado desde los inicios en estos debates. De conformidad con el artículo 7.6 de la CMNUCC, las empresas, a través de las organizaciones de empresarios o de manera individual, han asegurado un lugar como observadores que pueden llegar a influir en la diplomacia multilateral que tiene lugar en las Naciones Unidas. ${ }^{27}$ De hecho, el número de actores no estatales, como las empresas, que participan a nivel de observadores en las negociaciones climáticas, ha aumentado considerablemente en las últimas Conferencias de las Partes. ${ }^{28}$ Esto ha generado una mayor interacción entre actores estatales y no estatales en la gobernanza climática global. ${ }^{29}$

En este sentido, la capacidad de las empresas de participar — directa e indirectamente - en la formulación de normas internacionales es un tema que ha sido abordado en la doctrina legal. La suma del poder económico y político de las empresas les ha abierto un espacio privilegiado en foros internacionales, lo que les ha permitido articular sus prerrogativas a nivel internacional, que son incluso aplicables con prioridad a los ordenamientos jurídicos nacionales y llegan a crear interferencias en la soberanía de los Estados para regular los intereses públicos, como puede ser el cambio climático. $^{30}$

responsables de crímenes del clima sobre la COP 21, Bruselas, Corporate Europe Obversatory, 2015, p. 16.

27 El artículo 7.6 de la CMNUCC estipula que todo otro organismo u órgano, sea nacional o internacional, gubernamental o no gubernamental, competente en los asuntos abarcados por la Convención y que haya informado a la secretaría de su deseo de estar representado en un periodo de sesiones de la Conferencia de las Partes como observador, podrá ser admitido en esa calidad, a menos que se oponga un tercio de las partes presentes. $\mathrm{Al}$ respecto, véase, Nasiritousi, Naghmehet al., "The Roles of Non-State Actors in Climate Change Governance: Understanding Agency Through Governance Profiles”, International Environmental Agreements: Politics, Law and Economics, vol. 16, núm. 1, 2016, pp. 109-126.

28 Lövbrand, Eva et al., "Making Climate Governance Global: How UN Climate Summitry Comes to Matter in a Complex Climate Regime”, Environmental Politics, vol. 26, núm. 4, 2017, pp. 580-599.

29 Bäckstrand, Karin et al., "Non-State Actors in Global Climate Governance: From Copenhagen to Paris and Beyond", Environmental Politics, vol. 26, núm. 4, 2017, pp. 561-579.

30 Según Arato, "over the last few decades the multinational firm has become a powerful and increasingly autonomous international lawmaker - an author of its own rights and obligations under public international law. This transformation has come at stark cost to the state's capacity to regulate in the public interest, with only tenuous grounding in state con- 
En el marco de la Conferencia de las Partes de la CMNUCC cabe destacar la participación de las empresas del sector de hidrocarburos, cuya injerencia en la gobernanza climática global tiene como objetivo, entre otros, asegurar su crecimiento económico a través de la explotación de las reservas de combustibles fósiles existentes. ${ }^{31}$ Según datos de las organizaciones de la sociedad civil, las prácticas de cabildeo de las grandes empresas del sector de hidrocarburos y de las organizaciones de empresarios influyen en las negociaciones climáticas. Recientes investigaciones demuestran que, tras la adopción del Acuerdo de París, empresas como ExxonMobil, Shell, Chevron, BP y Total han invertido millones de dólares en campañas engañosas sobre el cambio climático y en prácticas de cabildeo, que favorecen la expansión de sus actividades. Esto afecta al desarrollo de políticas progresivas para alcanzar los objetivos establecidos en el régimen internacional del cambio climático. ${ }^{32}$

En consecuencia, las empresas, junto con algunos Estados, que generan beneficios de la crisis climática, obstaculizan las negociaciones, reducen las ambiciones de los Estados, promueven soluciones falsas y bloquean la financiación de posibles soluciones eficaces. ${ }^{33}$ Por ejemplo, la posición de la Cámara de Comercio Internacional, integrada por los directivos de las empresas de los Carbon Majors como BP, Shell o ExxonMobil, es que cualquier política climática adoptada en el marco de la CMNUCC debe incluir las prioridades de las empresas y, a su vez, es partidaria de que las acciones

sent”, Arato, Julian, “Corporations as Lawmakers”, Harvard International Law Journal, vol. 56, núm. 2, 2015, pp. 229-295. Véase también, Álvarez, José E., “Are Corporations Subjects of International Law?”, Santa Clara Journal of International Law, vol. 9, núm. 1, 2011, pp.1-35.

31 Nasiritousi, Naghmeh, op. cit., p. 643.

32 Según la investigación de la organización InfluenceMap, "[s]ince Paris, Chevron, BP and ExxonMobil have led in direct lobbying activities to oppose a range of progressive climate policy strands. Royal Dutch Shell and to some extent Total have made steps since 2015 to be more positive on a number of climate policy issues. However, both companies continue to support policy supporting a continued role for fossil fuels in the energy mix and remain part of highly climate-oppositional trade associations like the American Petroleum Institute”. Influence Map, Big Oil's Real Agenda on Climate Change, Londres, Influence Map, 2019, p. 2.

33 Corporate Accountability International et al., How Big Polluters are Undermining Global Climate Policy, Johanesburgo-Bruselas-Boston-Davo City, Corporate Accountability International, ActionAid, APMDD, CEO, ETC Group, 2017, p. 6. 
climáticas de estos agentes económicos deben ser de carácter voluntario. ${ }^{34}$ Por ello, la participación de las empresas en las negociaciones climáticas, principalmente las del sector de hidrocarburos, ha generado una gran controversia, hasta el punto de que otros actores no estatales han solicitado a los Estados parte de la CMNUCC que retiren el acceso a los representantes de las empresas de dicho sector. ${ }^{35}$

El Acuerdo de París crea una oportunidad para cambiar las dinámicas de las negociaciones climáticas, ya que sustituye el multilateralismo formal por la multipolaridad en la cooperación climática internacional. ${ }^{36}$ En consecuencia, el régimen internacional del cambio climático se descentraliza, lo que permite institucionalizar un nuevo papel para los agentes no estatales en la gobernanza climática global. ${ }^{37}$ De hecho, el Preámbulo de este instrumento reconoce la importancia del compromiso de los diversos actores, de conformidad con la legislación nacional de cada parte, al hacer frente al cambio climático. Esto incluso ha planteado la posibilidad de atribuir a los actores no estatales, incluidas las empresas, un papel activo en los procesos de revisión del Acuerdo de París: marco de transparencia (artículo 13), balance mundial (artículo 14) y mecanismo de aplicación y cumplimiento (artículo 16). ${ }^{38}$

Por tanto, en el marco del Acuerdo de París las obligaciones de reducción de emisiones recaen principalmente en los Estados. Mientras tanto, la reducción de emisiones de las empresas, por un lado, está proporcionalmente sujeta a los compromisos asumidos por los Estados en los que operan. Cabe destacar que más de la mitad de las primeras ND, comunicadas por los Estados a la secretaría de la CMNUCC, se han redactado y desarrollado a través de consultas con el sector privado. Sin embargo, no han incluido su com-

34 Corporate Accountability International, Inside Job: Big Polluters' Lobbyists on the inside at the UNFCCC, Londres, Corporate Accountability International, 2017, pp. 9 y 10.

35 Véase, "Kick Big Polluters Out Of Climate Policy. Petition to the Parties to the United Nations Framework Convention on Climate Change", disponible en: www.pollutersoutpeoplein. com (consultado el 1o. de octubre de 2019).

36 Salinas Alcega, Sergio, "El Acuerdo de París de diciembre de 2015: la sustitución del multilateralismo por la multipolaridad en la cooperación climática internacional”, Revista Española de Derecho Internacional, vol. 70, núm. 1, 2018, pp. 53-76.

37 Bäckstrand, Karin et al., op. cit., p. 562.

38 Van Asselt, Harro, "The Role of Non-State Actors in Reviewing Ambition, Implementation, and Compliance under the Paris Agreement”, Climate Law, vol. 6, núm. 1-2, 2016, pp. 91-108. 
promiso y el papel en la implementación de las estrategias y objetivos. ${ }^{39}$ En este sentido, el enfoque bottom up del Acuerdo de París podría favorecer que las empresas eligieran estratégicamente el lugar de sus operaciones, alejándose de aquellos Estados cuyos compromisos climáticos son más estrictos.

Por otro lado, la posibilidad de asumir compromisos más ambiciosos de reducción de emisiones por parte de las empresas permanece en el ámbito de la voluntariedad. La Decisión 1/CP.21, que acompaña la adopción del Acuerdo de París, invita a los interesados que no son partes, incluidos la sociedad civil, el sector privado, las instituciones financieras, las ciudades y otras autoridades subnacionales, a que acrecienten sus esfuerzos y apoyen las medidas destinadas a reducir las emisiones y a aumentar la resiliencia y disminuir la vulnerabilidad a los efectos adversos del cambio climático. ${ }^{40}$ La presión de la sociedad civil y de otros competidores en el mercado ha llevado a que algunas empresas respondan positivamente a este llamado, se impliquen de manera activa en la gobernanza climática global y propongan soluciones al problema. ${ }^{41}$ Para visibilizar y registrar dichos esfuerzos, se ha puesto en marcha la plataforma de la Zona de los Actores No Estatales (NAZCA) para la Acción Climática. ${ }^{42}$ En 2019, esta plataforma registra más de 5,000 acciones de más de 2,000 empresas. Sin embargo, no sólo el número de acciones varía de una empresa a otra, sino también el alcance y

39 En septiembre de 2019, 184 Estados parte habían inscrito en el registro público su primera NDC, según el artículo 4.12 del Acuerdo de París. Véase, "Interim NDC Registry", disponible en: www4.unfccc.int/sites/ndcstaging/Pages/Home.aspx (consultado el 1o. de octubre de 2019). Sobre un análisis de las primeras NDC y el papel del sector privado, véase GRI y CDP, "Engaging Business in the NDCs. Policy Recommendations on the Role of the Private Sector and Reporting", 2019, disponible en: www.globalreporting.org/SiteCollectionDocuments/2019/ NDCs\%20Policy-062019-CDP.pdf (consultado el 1o. de octubre de 2019).

40 Véase, "Decisión 1/CP.21. Aprobación del Acuerdo de París", disponible en: https: / / unfccc.int/resource/docs/2015/cop21/spa/10a01s.pdf (consultado el 1o. de octubre de 2019).

41 Nasiritousi, Naghmeh, op. cit., p. 643.

42 La plataforma NAZCA se lanzó en la conferencia sobre cambio climático de la ONU en Lima, en diciembre de 2014 (COP20). La NAZCA proporciona visibilidad y seguimiento de la diversidad de la acción climática por parte de los actores no estatales y genera un compromiso más amplio para ayudar a los países a alcanzar sus compromisos nacionales. Véase, "Non-State Actor Zonefor Climate Action (NAZCA)", disponible en: http: / / climateaction.unfccc.int/views/about.html (consultado el 1o. de octubre de 2019). Véase también, Wei, David, "Linking Non-State Action with the U.N. Framework Convention on Climate Change", disponible en: www.c2es.org/site/assets/uploads/2016/10/linking-nonstate-action-unfccc.pdf (consultado el 1o. de octubre de 2019). 
Esta revista forma parte del acervo de la Biblioteca Jurídica Virtual del Instituto de Investigaciones Jurídicas de la UNAM

DOI: http://dx.doi.org/10.22201/iij.24487872e_2020.20.14472

ambición de las mismas, lo que sigue manteniendo importantes divergencias en las acciones climáticas de las empresas.

\section{III. ¿HACIA LA CONFIGURACIÓN DE OBLIGACIONES CLIMÁTICAS PARA LAS EMPRESAS?}

Desde hace más de una década se debate tanto en el Consejo de Derechos Humanos (CDH) de las Naciones Unidas como en la Conferencia de las Partes de la CMNUCC sobre el impacto negativo del cambio climático en las condiciones necesarias para el disfrute de los derechos humanos. En el CDH, la Resolución 7/23 de 2008 señalaba que el cambio climático planteaba una amenaza inmediata y de gran alcance para la población y las comunidades de todo el mundo y tenía consecuencias adversas en el ejercicio pleno de los derechos humanos. ${ }^{43}$ Asimismo, la Resolución 10/4 de 2009 remarcó que los efectos relacionados con el cambio climático incidían, de diversas formas, en el disfrute efectivo de los derechos humanos y que esos efectos se sentían con más fuerza entre los grupos de población más vulnerables. ${ }^{44}$ Desde entonces, se han adoptado otras resoluciones similares en las que el $\mathrm{CDH}$ pone de manifiesto su preocupación por los efectos del cambio climático sobre los derechos humanos. ${ }^{45}$

En el marco de la Conferencia de las Partes de la CMNUCC, en 2009, se daba a conocer en Copenhague una declaración conjunta de 20 titulares de mandatos que hacía hincapié en que el cambio climático planteaba graves amenazas para el disfrute efectivo de un gran número de derechos huma-

43 Consejo de Derechos Humanos, Resolución 7/23. Los derechos humanos y el cambio climático, A/HRC/7/78 (14 de julio de 2008), pp. 68-70.

44 Consejo de Derechos Humanos, Resolución 10/4. Los derechos humanos y el cambio climático, A/HRC/10/L. (12 de marzo de 2009), pp. 14-16.

45 Consejo de Derechos Humanos, Resolución 18/22. Los derechos humanos y el cambio climático, A/HRC/RES/18/2 (11 de octubre de 2011); Consejo de Derechos Humanos, Resolución 26/27. Los derechos humanos y el cambio climático, A/HRC/RES/26/27 (15 de julio de 2014); Consejo de Derechos Humanos, Resolución29/15. Los derechos humanos y el cambio climático, A/HRC/RES/29/15 (22 de julio de 2015); Consejo de Derechos Humanos, Resolución 32/33. Los derechos humanos y el cambio climático, A/HRC/RES/32/33 (18 de julio de 2016). Consejo de Derechos Humanos, Resolución 41 \% Los derechos humanos y el cambio climático, A / HRC/41/L.24 (9 de julio de 2019). 
nos. ${ }^{46}$ En 2010, durante la conferencia celebrada en Cancún, se adoptó una decisión que señalaba que las partes, en todas las actividades relacionadas con el cambio climático, deberían respetar plenamente los derechos humanos. ${ }^{47}$ En Lima, en 2014, los titulares de mandatos instaban a los Estados a adoptar un nuevo instrumento en materia de cambio climático que estuviera estrechamente relacionado con el marco de los derechos humanos. ${ }^{48}$

En este contexto, el esfuerzo de los Estados y de la sociedad civil logró que el régimen internacional del cambio climático incluyera el reconocimiento expreso de la relación entre el cambio climático y los derechos humanos. ${ }^{49}$ Así, el Acuerdo de París ha sido reconocido como un instrumento de referencia, ya que es el primer acuerdo sobre el clima, y uno de los primeros acuerdos ambientales que contiene una referencia expresa a la relación entre el cambio climático y los derechos humanos. El Preámbulo del Acuerdo señala que el cambio climático es un problema de toda la humanidad y que, al adoptar medidas para hacerle frente, las partes deberían respetar, promover y tener en cuenta sus respectivas obligaciones relativas a los derechos humanos. Aunque la referencia a los derechos humanos en el Acuerdo de París ha sido calificada como simbólica, ${ }^{50}$ implica un reconocimiento por parte de la comunidad internacional de que el cambio climático plantea amenazas inaceptables al pleno disfrute de los derechos humanos y que las medidas para hacerle frente deben cumplir con las obligaciones en

46 Consejo de Derechos Humanos, Informe del Relator Especial sobre la cuestión de las obligaciones de derechos humanos relacionadas con el disfrute de un medio ambiente sin riesgos, limpio, saludable y sostenible, A/HRC/31/52 (1o. de febrero de 2016), párr. 11.

47 Véase, Decisión 1/CP.16 Acuerdos de Cancún: resultado de la labor del Grupo de Trabajo Especial sobre la cooperación a largo plazo en el marco de la Convención, FCCC/ CP/2010/7/Add. 1 (15 de marzo de 2011), párr. 8.

48 Consejo de Derechos Humanos, "Informe del Relator Especial sobre la cuestión de las obligaciones de derechos humanos...”, cit., párr. 15.

49 Sobre la relación entre el cambio climático y los derechos humanos, véase Duyck, Sébastien et al., Johl (eds.), Routledge Handbook of Human Rights and Climate Governance, Londres-Nueva York, Routledge, 2018; Quirico, Ottavio y Boumghar, Mouloud (eds.), Climate Change and Human Rights: An International and Comparative Law Perspective, Londres-Nueva York, Routledge, 2015; Humphreys, Stephen (ed.), Human Rights and Climate Change, Cambridge, Cambridge University Press, 2010.

50 Con relación al alcance y las implicaciones de la referencia a los derechos humanos en el Acuerdo de París, véase Boyle, Alan, "Climate Change, the Paris Agreement and Human Rights”, International and Comparative Law Quarterly, 2018, vol. 67, núm. 4, pp. 759-777. 
materia de derechos humanos. Por tanto, marca el punto de partida para clarificar y reforzar las obligaciones de los Estados - y las responsabilidades de las empresas - en materia de derechos humanos relacionadas con el cambio climático.

El anterior Relator Especial de las Naciones Unidas sobre la cuestión de las obligaciones de derechos humanos relacionadas con el disfrute de un medio ambiente sin riesgos, limpio, saludable y sostenible, John Knox, matiza e interpreta una lista no exhaustiva de obligaciones de los Estados en materia de derechos humanos relacionadas con el cambio climático. El profesor Knox señala que, entre otras cuestiones, los Estados deben controlar las actividades de las empresas que contribuyen al cambio climático. Los Estados tienen la obligación de adoptar y aplicar marcos jurídicos e institucionales para proteger ante los daños ambientales que interfieran o puedan interferir en el disfrute de los derechos humanos y responder a todas las violaciones de los derechos humanos causadas por la degradación ambiental, incluido el menoscabo de los derechos humanos con relación al cambio climático. Dichas obligaciones se aplican a los daños ambientales causados por empresas y otros actores privados. ${ }^{51}$ Esto implica que los Estados deben prevenir y remediar violaciones de derechos humanos asociadas a las emisiones de GEI de las empresas domiciliadas en su territorio o bajo su jurisdicción. ${ }^{52}$

En la economía mundo-capitalista, muchos Estados han fallado en su obligación de regular efectivamente las actividades de las empresas, lo que les ha permitido generar graves impactos sociales y ambientales, sin tener que rendir cuentas por los mismos. El incumplimiento de esta obligación puede motivar acciones internacionales por las violaciones de derechos humanos asociados a los impactos del cambio climático. En este sentido, en 2013, la organización Earth justice, en nombre del pueblo de Athabaskan que habita en el Ártico, interpuso una petición ante la Comisión Interamericana

51 Consejo de Derechos Humanos, "Informe del Relator Especial sobre la cuestión de las obligaciones de derechos humanos...”, cit., párrs. 23-32 y 66-67.

52 En un sentido similar, la Observación general número 36 del Comité de Derechos Humanos señala que la implementación de la obligación de los Estados de respetar y garantizar el derecho a la vida implica la adopción de medidas para proteger el medio ambiente frente al cambio climático causado por actores privados. Comité de Derechos Humanos, General comment No. 36 (2018) on article 6 of the International Covenant on Civil and Political Rights, on the right to life, CCPR/C/GC/36 (30 de octubre de 2018), párr. 62. 
de Derechos Humanos. ${ }^{53}$ En este caso, aún pendiente de resolver, se alega que Canadá ha fallado en su obligación de regular y limitar las emisiones de carbono negro (hollín), que contribuyen al cambio climático. Por ende, se generaron impactos directos en el Ártico que afectan la salud, cultura, propiedad y medios de subsistencia del pueblo de Athabaskan, lo que vulnera derechos contemplados en la Declaración Americana de los Derechos y Deberes del Hombre. ${ }^{54}$ Este caso no tiene posibilidades de llegar a la Corte Interamericana de Derechos Humanos, ya que Canadá no ha aceptado la competencia de este tribunal internacional. Sin embargo, se trata de un precedente importante que podría concluir en una serie de recomendaciones sobre cómo los Estados deben regular las emisiones de determinadas empresas y sectores industriales para evitar incurrir en una responsabilidad internacional por violaciones de derechos humanos asociadas a los impactos del cambio climático.

Por otra parte, la comunidad internacional debate en el seno de las $\mathrm{Na}$ ciones Unidas la viabilidad de imponer obligaciones directas a las empresas de promover y respetar los derechos humanos reconocidos en los instrumentos internacionales. En 2014, el CDH adoptó la histórica Resolución 26/9, que estableció un grupo de trabajo intergubernamental para elaborar un tratado que regule las actividades de las empresas transnacionales en virtud del derecho internacional de los derechos humanos. ${ }^{55}$ En el marco de las negociaciones de este tratado, algunos Estados y organizaciones de la sociedad civil se muestran a favor de que el futuro instrumento incluya obligaciones directas para las empresas. No obstante, esta cuestión ha encontrado una fuerte oposición, principalmente de los Estados del norte global y de las empresas, que manifiestan que este instrumento debería mantener

53 Earthjustice, "Petition to the Inter-American Commission on Human Rights Seeking Relief from Violations of the Rights of Arctic Athabaskan Peoples Resulting from Rapid Arctic Warming and Melting Caused by Emissions of Black Carbon by Emissions of Black Carbon by Canada”, disponible en: https: / / earthjustice.org/sites/default/files/AAC_PETITION_13-04-23a. pdf (consultado el 1o. de octubre de 2019).

${ }^{54}$ McCrimmon, Don, "The Athabaskan Petition to the Inter-American Human Rights Commission: Using Human Rights to Respond to Climate Change”, The Polar Journal, vol. 6, núm. 2, 2016, pp. 398-416.

55 Consejo de Derechos Humanos, Elaboración de un instrumento internacional jurídicamente vinculante sobre las empresas transnacionales y otras empresas con respecto a los derechos humanos, A/ $\mathrm{HRC} / \mathrm{RES} / 26 / 9$ (26 de junio de 2014). 
el statu quo del derecho internacional y, por ende, imponer únicamente obligaciones a los Estados. ${ }^{56}$

Si bien los Estados, las organizaciones de la sociedad civil y las empresas no se ponen de acuerdo sobre la imposición de obligaciones directas en virtud del derecho internacional, existe un mayor consenso a nivel internacional con relación a la responsabilidad de las empresas de respetar los derechos humanos. Esto se diferencia de la responsabilidad legal por el incumplimiento de normas y, más allá de configurar obligaciones y deberes, ${ }^{57}$ se trata de una expectativa social que consiste en que las empresas se abstengan de infringir los derechos humanos de terceros y hacer frente a las consecuencias negativas sobre los derechos humanos en las que tengan alguna participación. ${ }^{58}$ La responsabilidad de las empresas de respetar los derechos humanos se ha reconocido como una norma de conducta global aplicable a todas las empresas dondequiera que operen, sin importar su tamaño, sector, contexto operacional, propietario y estructura. Asimismo, es independiente a la capacidad o voluntad de los Estados de cumplir sus propias obligaciones de derechos humanos y no reduce esas obligaciones. ${ }^{59}$

Esta responsabilidad se extiende a los derechos humanos reconocidos internacionalmente, y requiere que las empresas eviten que sus propias actividades provoquen o contribuyan a provocar consecuencias negativas sobre los derechos humanos y que hagan frente a los efectos que se produzcan. Además, deben tratar de prevenir o mitigar riesgos e impactos sobre los

56 Iglesias Márquez, Daniel, "Explorando las fronteras del derecho internacional de los derechos humanos: hacia la adopción de un tratado internacional sobre empresas y derechos humanos", Akademía. Revista Internacional y Comparada de Derechos Humanos, 2018, vol. 1, núm. 1 , pp. 165-214.

57 El professor Ruggie especifica que "the corporate responsibility to respect rights, rather than duty, to indicate that respecting rights is not an obligation current international human rights law generally imposes directly on companies", Ruggie, John G., "The Construction of the UN "Protect, Respect and Remedy", Framework for Business and Rights: The True Confessions of a Principled Pragmatist”, European Human Rights Law Review, 2011, núm. 2, pp. 127-133.

58 Deva, Surya, "Treating Human Rights Lightly: A Critique of the Consensus Rhetoric and the Language Employed by the Guiding Principles”, en Deva, Surya y Bilchitz, David (eds.), Human Rights Obligations of Business Beyond the Corporate Responsibility to Respect?, Cambridge, CUP, 2013, pp. 78-104.

59 Consejo de Derechos Humanos, La responsabilidad de las empresas de respetar los derechos humanos, Nueva York-Ginebra, Consejo de Derechos Humanos, 2012, pp. 11-26. 
derechos humanos directamente relacionados con operaciones, productos o servicios prestados por sus relaciones comerciales, incluso cuando no hayan contribuido a generarlas. Se entiende por relaciones comerciales a las entidades de su cadena de valor y cualquier otra entidad no estatal o estatal directamente relacionada con sus operaciones comerciales, productos o servicios.

Teniendo en cuenta que las emisiones de GEI, resultado de las actividades empresariales, tienen consecuencias cualitativas en el disfrute de los derechos humanos, la responsabilidad de las empresas de respetar los derechos humanos implica un compromiso implícito de mantener el aumento de la temperatura media mundial por debajo de $2{ }^{\circ} \mathrm{C}$ con respecto a los niveles preindustriales. En el caso en contra de la empresa Shell en los Países Bajos, "the claimants come to the conclusion that Shell, with its current inadequate climate policy... violates the right to life and the right to an undisturbed family life as stipulated in Articles 2 and 8 of the [European Convention on Human Rights]. ${ }^{60}$ Por tanto, "[t]he claimants are of the opinion that the adopted Paris climate target, which aims to prevent dangerous climate change, also has a legal meaning for Shell". ${ }^{61}$

En este sentido, la Oficina del Alto Comisionado de las Naciones Unidas para los Derechos Humanos, en su contribución escrita a la Conferencia de las Partes de la CMNUCC en París, señaló que "[b]usinesses are alsodutybearers. They must be accountable for their climate impacts and participate responsibly in climate change mitigation and adaptation efforts with full respect for human rights". ${ }^{62}$ Por ende, las empresas deben operar de manera responsable y respetar los derechos humanos, lo que implica que deben adoptar medidas para reducir sus emisiones de GEI. ${ }^{63}$

60 Véase, Milieu defensie et al. vs. Royal Dutch Shell plc, Un official translation of the summons, disponible en: http://climatecasechart.com/non-us-case/milieudefensie-et-al-v-royal-dutchshell-plc/, párr. 55 (consultado el 1o. de octubre de 2019).

61 Ibidem, párr. 38

62 Véase, "Submission of the Office of the High Commissioner for Human Rights to the 21st Conference of the Parties to the United Nations Framework Convention on Climate Change", disponible en: www.ohchr.org/Documents/Issues/ClimateChange/COP21.pdf (consultado el 1o. de octubre de 2019).

63 En palabras del anterior Alto Comisionado Zeid Ra' ad Al Hussein, “[b]usinesses must behave responsibly and respect human rights, including by taking measures to cut their greenhouse emissions". Véase, "Zeid urges climate change ambition as Paris deal enters into force”, dis- 
Por su parte, el actual relator especial sobre los derechos humanos y el medio ambiente, David R. Boyd, ha identificado cinco estándares climáticos asociados a la responsabilidad de las empresas de respetar los derechos humanos: i) reducir las emisiones de gases de efecto invernadero de sus propias actividades y filiales; ii) reducir las emisiones de gases de efecto invernadero de sus productos y servicios; iii) reducir al mínimo las emisiones de gases de efecto invernadero de sus proveedores; iv) informar públicamente de sus emisiones, su vulnerabilidad al clima y su riesgo de activos en desuso, y v) garantizar que las personas afectadas por violaciones de los derechos humanos relacionadas con las empresas tengan acceso a recursos eficaces. Asimismo, el relator especial indica que las empresas deberían apoyar las políticas públicas destinadas a hacer frente al cambio climático de manera eficaz, en lugar de oponerse a ellas. ${ }^{64}$

Como se detalla en los siguientes epígrafes, algunos instrumentos internacionales de soft law que promueven la responsabilidad de respetar los derechos humanos contienen o clarifican estándares que contribuyen a prevenir y a rendir cuentas de las emisiones de GEI de las actividades empresariales. Así, se sientan las bases para un sistema de corresponsabilidad entre los Estados y las empresas para generar acciones de mitigación y adaptación frente a este fenómeno de consecuencias globales, así como para distribuir la carga de los costes de sus impactos. Algunos de estos instrumentos son: los Principios Rectores sobre las Empresas y los Derechos Humanos, las Líneas Directrices de la Organización para la Cooperación y el Desarrollo Económicos (OCDE) para Empresas Multinacionales y los Principios sobre Obligaciones Climáticas de las Empresas, que se analizan a continuación.

1. Los Principios Rectores sobre las Empresas y los Derechos Humanos

En 2011, mediante la Resolución 17/4 del CDH, se aprobaron los Principios Rectores de las Naciones Unidas sobre las Empresas y los Derechos Humanos (en adelante, Principios Rectores). Estos Principios ponen en

ponible en: www.ohchr.org/EN/NewsEvents/Pages/DisplayNews.aspx? NewsID=20822\&LangID =E (consultado el 1o. de octubre de 2019).

64 Consejo de Derechos Humanos, Informe del Relator Especial sobre la cuestión de las obligaciones de derechos humanos relacionadas con el disfrute de un medio ambiente sin riesgos, limpio, saludable y sostenible, A/74/161 (15 de julio de 2019), párr. 72. 
práctica los tres pilares del marco de las Naciones Unidas: "Proteger, Respetar y Remediar". ${ }^{65}$ Este instrumento cuenta con un enfoque predominantemente de carácter soft law. Los Principios Rectores fueron el resultado de un proceso conducido durante el mandato del representante especial del secretario general sobre la cuestión de los derechos humanos y las empresas transnacionales y otras empresas comerciales, John Ruggie.

El marco de los Principios Rectores está basado en tres pilares, que agrupan 31 principios y sus comentarios respectivos: 1) la obligación de proteger los derechos humanos por parte de los Estados, 2) la responsabilidad de respetar los derechos humanos por parte de las empresas, y 3) el acceso a la reparación por parte de las víctimas de vulneraciones de derechos humanos. Una de las omisiones importantes que se puede identificar en los Principios Rectores es la carencia de una dimensión ambiental. ${ }^{66} \mathrm{~A}$ pesar de que los informes preparatorios del profesor Ruggie demuestran que los impactos ambientales de las actividades empresariales tienen efectos adversos en el disfrute de los derechos humanos, ${ }^{67}$ la estructura y el enfoque de este instrumento no abordan directamente las obligaciones y responsabilidades de los Estados y de las empresas de proteger el medio ambiente o su valor intrínseco para el disfrute de los derechos humanos.

El principio 12 de los Principios Rectores enlista una serie de instrumentos que enuncian los derechos que las empresas deben respetar en el desarrollo de sus operaciones. Entre ellos se encuentran aquellos consagrados en la Carta Internacional de Derechos Humanos y los principios relativos a los derechos fundamentales establecidos en la Declaración de la Organización Internacional del Trabajo relativa a los principios y derechos fundamentales en el trabajo. Asimismo, deben respetar los derechos de los pueblos indígenas, las mujeres, las minorías nacionales, étnicas, religiosas y

65 Representante especial del secretario general sobre la cuestión de los derechos humanos y las empresas transnacionales y otras empresas comerciales, Principios Rectores sobre las empresas y los derechos humanos: Puesta en práctica del marco de las Naciones Unidas para "proteger, respetar y remediar”, A/HRC/17/31 (21 de marzo de 2011).

66 Deva, Surya, "Taking Nature Seriously. Can the UN Guiding Principles Tame Corporate Profiteering?", en Voigt, Christina (ed.), Rule of Law for Nature. New Dimensions and Ideas in Environmental Law, Cambridge, CUP, 2013, pp. 312-328.

67 Consejo de Derechos Humanos, Empresas y Derechos Humanos: Encuesta sobre el alcance y los tipos de presuntos abusos de los derechos humanos cometidos por empresas, A/HRC/8/5/Add.2 (23 de mayo de 2008), párr. 27. 
lingüísticas, los niños y las niñas, las personas con discapacidad y los trabajadores migrantes y sus familias. Por otra parte, en situaciones de conflicto armado, las empresas deben respetar las normas del derecho internacional humanitario. No obstante, en esta lista no se hace referencia al respeto de las normas internacionales en materia de medio ambiente.

A la luz de lo anterior, es posible afirmar que los Principios Rectores no hacen una referencia directa al cambio climático ni a los instrumentos del régimen internacional en esta materia. ${ }^{68}$ Sin embargo, se acepta y explora cada vez más la aplicación del segundo pilar de los Principios Rectores en el contexto del cambio climático. ${ }^{69}$ En 2018, durante el Séptimo Foro de las Naciones Unidas sobre Empresas y Derechos Humanos, se dedicó una de las sesiones a debatir sobre cuáles eran las responsabilidades de las empresas en materia de derechos humanos que se aplican al contexto del cambio climático, especialmente con el fin de determinar las acciones de las empresas para alcanzar una transición energética efectiva. Esto supuso un avance significativo, teniendo en cuenta la poca atención que ha tenido la cuestión del cambio climático en este espacio multi actor dedicado a intercambiar experiencias y aprender de las numerosas iniciativas destinadas a promover el respeto de los derechos humanos por parte de las empresas. ${ }^{70}$

68 A pesar de que los principios rectores no hacen referencia directa al cambio climático, algunos planes de acción nacional (PAN) sobre empresas y derechos humanos, que son los instrumentos políticos empleados por los Estados para la implementación de los principios rectores a nivel nacional, contienen un llamado a las empresas para la lucha contra el cambio climático. Por ejemplo, el PAN de Francia contempla la siguiente acción: Implement the UN Guiding Principles in the battle against climate change, following commitments made during COP 21. Véase, "Plan National de mise en œuvre des Principes directeurs des Nations Unies pour les droits de l'Homme et les entreprises", disponible en: www.ohchr.org/Documents/Issues/Business/NationalPlans/NAP_Actions_France_EN.pdf, p. 2 (consultado el 1o. de octubre de 2019). Otros PAN que hacen referencia al cambio climático son los de Bélgica, Chile, Italia, Luxemburgo, Noruega y Estados Unidos. Disponible en: https://globalnaps.org/issue/environmentand-climate-change/ (consultado el 1o. de octubre de 2019).

69 Cfr., "Private actors also have obligations to address the human rights implications of climate change, and should refer to the UN Guiding Principles on Business and Human Rights to ensure that they fully respect human rights in all activities", UNEP, Climate Change and Human Rights, Nairobi, UNEP, 2015, p. IX.

70 Seck, Sara, "Reflections on Business, Human Rights, the Environment, and Climate Justice”, Dalhousie University Environmental Law News Blog, 4 de diciembre de 2017, disponible en: https: / / blogs.dal.ca/melaw/2017/12/04/reflections-on-business-human-rights-the-environmentand-climatejustice-december-4-2017/ (consultado el 1o. de octubre de 2019). 
Por su parte, el profesor Boyd indica que la primera medida que las empresas deben adoptar para hacer frente al cambio climático es la implementación de los Principios Rectores sobre las Empresas y los Derechos Humanos. ${ }^{71}$ En un sentido similar, el informe titulado Achieving Justice and Human Rights in an Era of Climate Disruption ${ }^{72}$ de 2014, de la International Bar Association (IBA), hace un llamado a que las empresas adopten e implementen los Principios Rectores, ya que se trata de un instrumento que se enmarca dentro del ámbito de derechos humanos y cambio climático. ${ }^{73}$ Por tanto, de conformidad con los Principios Rectores, el informe recomienda el desarrollo de un compromiso político de las empresas con los derechos humanos aplicable al contexto del cambio climático, que incluya los siguientes elementos: 1) la adopción de una declaración política, 2) la implementación de un proceso de diligencia debida en materia de derechos humanos, y 3) el establecimiento de mecanismos de reclamación eficaces a nivel operacional. ${ }^{74}$

Con relación al primer elemento, el Principio 16 de los Principios Rectores establece que las empresas deben expresar su compromiso de respetar los derechos humanos mediante una declaración política que establezca lo que la empresa espera, con relación a los derechos humanos, de su personal, sus socios y otras partes directamente vinculadas con sus operaciones, productos y servicios. Por su parte, el informe de la IBA especifica que la declaración política debe estipular explícitamente las medidas diseñadas para prevenir y mitigar los impactos adversos del cambio climático relacionados con sus operaciones. Este compromiso político se debe hacer público, ser aprobado por el más alto nivel directivo y extenderse a sus relaciones comerciales. En este sentido, es cierto que, cada vez más, las empresas adoptan políticas en materia de cambio climático y participan en

71 Consejo de Derechos Humanos, "Informe del Relator Especial sobre la cuestión de las obligaciones de derechos humanos...”, cit., párr. 71.

72 IBA, Achieving Justice and Human Rights in an Era of Climate Disruption, Londres, IBA, 2014. Véase también Seck, Sara L. y Slattery, Michael, "Business, Human Rights and the IBA Climate Justice Report”, Journal of Energy \& Natural Resources Law, 2016, vol. 34, núm. 1, pp. $75-85$.

73 IBA, op. cit., p. 147.

74 Ibidem, pp. 48-149; Amis, Lucy, A Guide for Business: How to Develop a Human Rights Policy, United Nations Global Compact Office-Office of the United Nations High Commissioner for Human Rights, 2011. 
iniciativas sectoriales para formular acciones que permitan hacer frente al cambio climático. ${ }^{75}$ No obstante, en estas políticas a menudo escasean las medidas concretas para la reducción de GEI, o bien, las acciones climáticas contempladas carecen de una perspectiva de derechos humanos alienada con el Acuerdo de París. ${ }^{76}$

En segundo lugar, el proceso de diligencia debida en materia de derechos humanos está contemplado en el Principio 17. Según el informe IBA, este proceso de diligencia debida se debe implementar de manera que aborde los impactos climáticos reales y potenciales de las actividades que puedan crear interferencia en el disfrute de los derechos humanos. La implementación de la diligencia debida debe resultar en medidas concretas para reducir los impactos negativos sobre los derechos humanos asociados a los impactos climáticos de sus actividades. ${ }^{77}$

Por lo anterior, las empresas pueden recurrir a otros instrumentos de gestión de riesgos ambientales para identificar los impactos climáticos a los que contribuyen sus operaciones o productos, con el fin de responder con las medidas de prevención o mitigación adecuadas. La Organización Internacional de Normalización (ISO) ha establecido una serie de normas dirigidas a empresas, gobiernos, proponentes de proyectos y otras partes interesadas, que contienen los principios y requisitos para la cuantificación, el seguimiento, la divulgación de información, la verificación de emisiones directas e indirectas y la absorción de GEI (ISO 14064-1:2018, ISO 14064-2:2006, ISO 14064-3:2006, ISO 14065:2013, ISO 14066:2011, ISO 14067:2018 e ISO/TR 14069:2013). La norma ISO 14064-1:2018, por ejemplo, junto con el Informe Técnico ISO/TR 14069:2013, contiene principios, conceptos y métodos relacionados con la cuantificación y la divulgación de información de emisiones de GEI directas e indirectas. Estos

75 Por ejemplo, algunas de las empresas del sector de hidrocarburos participan en la Oil and Gas Climate Initiative, que tiene como objetivo catalizar acciones prácticas en materia de cambio climático, con el fin de reducir su huella de carbono. Véase, https: / / oilandgasclimateinitiative.com/ (consultado el 1o. de octubre de 2019).

76 Alliance for Corporate Transparency, "2018 Research Report The state of corporate sustainability disclosure under the EU Non-Financial Reporting Directive”, 2019, disponible en: www.allianceforcorporatetransparency.org/assets/2018_Research_Report_Alliance_Corporate_ Transparency-66d0af6a05f153119e7cffe6df2f1 1b094affe9aaf4b13ae14db04e395c54a84.pdf, pp. 30-33 (consultado el 1o. de octubre de 2019).

77 IBA, op. cit., p. 147. 
instrumentos, de carácter voluntario, contribuyen a establecer los límites operativos de emisiones de GEI, así como a mejorar la transparencia y coherencia de la divulgación de información relacionada con las emisiones de GEI. ${ }^{78}$ Las directrices del Carbon Disclosure Project constituyen otro mecanismo para divulgar información sobre las emisiones de GEI de las actividades y productos, ya que establecen un sistema de divulgación global para inversores, empresas, ciudades, Estados. ${ }^{79}$

En un contexto global de mayor transparencia, han surgido diversas iniciativas a nivel nacional e internacional de divulgación de información sobre los impactos de las actividades de las empresas. A pesar de que estas iniciativas varían tanto en contenido como en alcance, ${ }^{80}$ su objetivo es brindar la información necesaria a todas las partes afectadas y generar una mayor participación en la planeación e implementación de los proyectos y actividades de las empresas. En este sentido, los Estados han adoptado normas vinculantes que imponen a determinadas empresas la obligación de divulgar información de contenido social y ambiental relacionadas con sus operaciones. ${ }^{81}$ En el ámbito europeo, la Directiva 2014/95/UE del Parlamento Europeo y del Consejo del 22 de octubre de 2014 por la que se modifica la Directiva 2013/34/UE en lo que respecta a la divulgación de información no financiera e información sobre diversidad, por parte de determinadas

78 Véase, "ISO 14064-1:2018, Greenhouse gases - Part 1: Specification with guidance at the organization level for quantification and reporting of greenhouse gas emissions and removals", disponible en: www.iso.org/obp/ui\#iso:std:iso:14064:-1:ed-2:v1:en (consultado el 1o. de octubre de 2019); "ISO/TR 14069:2013, Gases de efecto invernadero-Cuantificación e informe de las emisiones de gases de efecto invernadero para las organizacionesOrientación para la aplicación de la Norma ISO 14064 1", disponible en: www.iso.org/obp/ ui\# iso:std:iso:tr:14069:ed-1:v1:es (consultado el 1o. de octubre de 2019).

79 Véase, Carbon Disclosure Project, disponible en: www.cdp.net/es (consultado el 1o. de octubre de 2019).

80 OECD y CDSB, Climate Change Disclosure in G20. Countries Stocktaking of Corporate Reporting Schemes, París-Londres, OECD-CDSB, 2015.

81 Con relación a la imposición de obligaciones de divulgación de información no financiera a las empresas, Nolan señala que "[t]he assumption in this disclosure model appears to be that the transparency gained from disclosure will incentivize corporate action to address human rights risks, because of the greater visibility of these risks that will be evident to investors and consumers. It relies on the voices of external stakeholders to hold companies to account by assessing and critiquing the corporate reports", Nolan, Justine, "Hardening Soft Law: Are the Emerging Corporate Social Disclosure Laws Capable of Generating Substantive Compliance with Human Rights?", Revista de Direito Internacional, vol. 15, núm. 2, 2018, pp. 65-83. 
empresas grandes y grupos, promueve la implementación de los Principios Rectores (Considerando 9). ${ }^{82}$ Esta Directiva establece que, a efectos de mejorar la coherencia y la comparabilidad de la información no financiera divulgada en la Unión, las empresas que cumplan determinados requisitos ${ }^{83}$ deben preparar un estado no financiero que contenga información relativa, por lo menos, a cuestiones ambientales y sociales. También debe contener información relativa al personal, al respeto de los derechos humanos, a la lucha contra la corrupción y el soborno y a las políticas que aplica el grupo en relación con dichas cuestiones, que incluya los procedimientos de diligencia debida aplicados. La Directiva ha sido transpuesta a los ordenamientos jurídicos de los 28 Estados miembros de la Unión Europea (UE).$^{84}$ Por tanto, sus disposiciones son exigibles a las empresas domiciliadas en la UE, así como a sus cadenas de suministro y subcontratación, cuando sea pertinente y proporcionado, con el fin de detectar, prevenir y atenuar los efectos adversos existentes y potenciales de sus actividades.

En materia de cambio climático, la Directiva 2014/95/UE establece que el estado no financiero debe incluir información detallada sobre las emisiones de GEI. Según la Comisión Europea, este requisito se enmarca en los objetivos del Acuerdo de París, ya que se espera que una mayor transparencia conduzca a flujos financieros más coherentes con una evolución hacia bajas emisiones de GEI y un desarrollo resiliente al cambio climático. En este sentido, la Alliance for Corporate Transparency ha evaluado la implementación de la Directiva 2014/95/UE en la práctica de más de 100 empresas del sector de la energía y extracción de recursos, de las tecnologías de la información y la comunicación y de la asistencia médica. Los resultados demuestran que la gran mayoría de las empresas evaluadas incorporan cuestiones de cambio climático en sus estados no financieros. La información

82 DO L 330 de 15.11.2014, pp. 1-9, disponible en: https: / /eur-lex.europa.eu/legal-content $/ E S / T X T /$ ? uri=celex\%3A32014L0095 (consultado el 1o. de octubre de 2019).

83 El ámbito de aplicación de los requisitos sobre divulgación de información no financiera debe definirse en función del número medio de empleados, del total del balance y del volumen de negocios neto. Por tanto, la Directiva 2014/95/UE estipula que las obligaciones de divulgación de información no financiera se aplican a las grandes empresas que sean entidades de interés público que, en sus fechas de cierre del balance, superen el criterio de un número medio de empleados superior a 500 durante el ejercicio.

84 Véase, Global Reporting Initiative (GRI) et al., Member State Implementation of Directive 2014/95/EU. A comprehensive overview of how Member States are implementing the EU Directive on Non-financial and Diversity Information, Bruselas-Ámsterdam, GRI-CRS Europe, 2017. 
presentada por las empresas incluye desde políticas climáticas hasta la cantidad de emisiones de GEI, objetivos específicos de reducción de emisiones de GEI y medidas de adaptación y mitigación de los riesgos asociados a los impactos del cambio climático. ${ }^{85}$

Finalmente, el principio 22 establece que si las empresas han generado o contribuido a generar consecuencias negativas deben repararlas o contribuir a su reparación por medios legítimos. Los mecanismos de reclamación a nivel operacional deben atender quejas interpuestas por los posibles afectados por los impactos climáticos de sus actividades. Estos mecanismos no deben interferir con los mecanismos judiciales y deben ser legítimos, accesibles, predecibles, equitativos, transparentes y compatibles, así como constituir una fuente de conocimiento continuo (principio 31), con el fin de dar una solución temprana a las quejas de los afectados por los impactos climáticos a los que contribuyen las empresas. En el caso Lliuya vs. RWE $E^{86}$ en la jurisdicción de Alemania, el afectado, antes de recurrir a la sede judicial, presentó una queja a la empresa en la que exponía los peligros que generaban sus emisiones de GEI y, por ello, solicitaba una indemnización para adoptar las medidas para prevenir posibles inundaciones. No obstante, $R W E$ respondió que la queja carecía de fundamento legal y, por tanto, no era responsable de otorgar la indemnización correspondiente. ${ }^{87}$

85 Alliance for Corporate Transparency, op. cit., p. 33.

86 En noviembre de 2015, un agricultor de la región andina del Perú, Saúl Luciano Lliuya, con apoyo de la ONG Germanwatch, interpuso una demanda en contra de la empresa productora de electricidad RWE ante los tribunales alemanes (20171130 Case No-2-O-28515). En este caso se alega que la empresa es parcialmente responsable del deshielo de los glaciares en la cercanía de Huaraz, ciudad donde habita el demandante. El demandante solicita el pago de aproximadamente 21,000 euros en concepto del coste de las medidas de protección y seguridad para hacer frente a las inundaciones de los lagos glaciares, los derrumbes, la probable inundación de su aldea y la destrucción de su propiedad. A la fecha de escritura del presente artículo, el caso aún está pendiente de resolverse. Véase, García-Álvarez, Laura, "El caso Huaraz: David contra Goliat o «Saúl L. contra RWE AG»: Un precedente clave en la justicia climática”, Revista Aranzadi de Derecho Ambiental, núm. 40, 2018, pp. 63-101.

87 Business \& Human Rights Resource Centre, "Demanda contra RWE (sobre cambio climático)", disponible en: www.business-humanrights.org/es/demanda-contra-rwe-sobre-cambioclim\%C3\%A1 tico (consultado el 1o. de octubre de 2019). 


\section{Líneas Directrices de la OCDE para Empresas Multinacionales}

En 1976, los Estados miembros de la OCDE adoptaron las Líneas Directrices para Empresas Multinacionales (Líneas Directrices) en el marco de la Declaración sobre Inversión Internacional y Empresas Multinacionales. ${ }^{88}$ Las Líneas Directrices son un código de conducta empresarial responsable, exhaustivo y acordado multilateralmente, que contiene recomendaciones de carácter no vinculante dirigidas a las empresas multinacionales que operan en países adherentes o que tienen su sede en ellos. Actualmente, 46 gobiernos de países miembros y no miembros de la OCDE se han adherido a las Líneas Directrices. ${ }^{89}$ Se trata de un instrumento soft law de gran aceptación, tanto en el sector público como en el privado, que ha sido revisado en cinco ocasiones (1979, 1984, 1991, 2000 y 2011) para incorporar elementos sustantivos que se adecuen a las exigencias del contexto socioeconómico global en el que se aplican. ${ }^{90}$

Como resultado de la última revisión, de 2011, las Líneas Directrices contienen once capítulos. ${ }^{91}$ Cabe destacar que la adopción de los Principios Rectores motivó la última revisión de las Líneas Directrices, con el fin de alienarse con los desarrollos alcanzados en el marco de las Naciones Unidas. En consecuencia, la revisión de 2011 tuvo como novedad principal la inclusión de un capítulo sobre derechos humanos y la adopción de un enfoque

88 OCDE, Líneas Directrices de la OCDE para Empresas Multinacionales, París, OECD Publishing, 2013.

89 Véase, “About the OECD Guidelines for Multinational Enterprises”, disponible en: http: / / mneguidelines.oecd.org/about/ (consultado el 1o. de octubre de 2019).

90 Sobre las Líneas Directrices y su alcance normativo para imponer estándares sociales y ambientales, véase, De Schutter, Olivier, "The Challenge of Imposing Human Rights Norms on Corporate Actors", en De Schutter, Olivier (ed.), Transnational Corporations and Human Rights, Oxford, Hart, 2006, pp. 1-39; Murray, Jill, “A New Phase in the Regulation of Multinational Enterprises: the Role of the OECD”, Industrial Law Journal, vol. 30, núm. 3, 2001, pp. 255-270; Karl, Joachim, “The OECD Guidelines for Multinational Enterprises”, en Addo, Michael K. (ed.), Human Rights Standards and the Responsibility of Transnational Corporations, La Haya, Kluwer Law International, 1999, pp. 89-106.

91 Černič, Jernej Letnar, "The 2011 Update of the OECD Guidelines for Multinational Enterprises”, American Society of International Law Insights, vol. 16, núm. 4, 2012, pp. 1-5. 
nuevo y amplio en relación con el principio de diligencia debida y con la gestión responsable de la cadena de suministro. ${ }^{92}$

A diferencia de los Principios Rectores, las Líneas Directrices sí contienen recomendaciones específicas en materia de medio ambiente sobre cómo mejorar el comportamiento ambiental de las empresas mediante la reducción de emisiones contaminantes, la eficiencia en el uso de recursos, la gestión de residuos tóxicos y la conservación de la biodiversidad.$^{93} \mathrm{El}$ objetivo del capítulo sobre medio ambiente es que las empresas lo protejan en el marco de las disposiciones legales y regulatorias y de las prácticas administrativas de los países en los que ejercen su actividad, considerando acuerdos, principios, objetivos y normas internacionales pertinentes. El contenido de este capítulo se encarga de compilar algunos de los objetivos y principios de instrumentos internacionales en materia ambiental, como la Declaración de Río, la Agenda 21, la Primera Declaración de Copenhague sobre Desarrollo Social y el Convenio de Aarhus sobre Acceso a la Información, Participación Pública en la Toma de Decisiones y Acceso a la Justicia en materia de medio ambiente. ${ }^{94}$

Las Líneas Directrices incorporan recomendaciones generales en materia de cambio climático. Durante el proceso de revisión de 2011 se propuso que se clarificara la aplicación de este instrumento en la lucha contra este fenómeno. ${ }^{95}$ Esto tuvo como resultado modificaciones en el capítulo de divulgación de información y el fortalecimiento del capítulo sobre medio ambiente, incluyendo recomendaciones para que las empresas adopten un

92 Ruggie, John y Nelson, Tamaryn, "Human Rights and the OECD Guidelines for Multinational Enterprises: Normative Innovations and Implementation Challenges", Corporate Social Responsibility InitiativeWorking Paper No.66, Cambridge, John F. Kennedy School of Government, Harvard University.

93 Al respecto, véase, Iglesias Márquez, Daniel, La regulación de las empresas transnacionales domiciliadas en la Unión Europea en relación con sus estándares de comportamiento y su responsabilidad por los daños ambientales causados en terceros Estados, tesis doctoral, Universitat Rovira i Virgili, 2017, pp. 144-150 y bibliografía allí citada.

94 OCDE, op. cit., p. 48.

95 Véase, "International Bar Association Working Group on the OECD Guidelines for Multinatioal Enterprises: Response to the UK Department for Business, Innovation \& Skills Consultation on the Terms of Reference for an Update of the OECD Guidelines for Multinational Enterprises", disponible en: https: / / www.ibanet.org/LPD/BHR-Committee/WG_Response_to_the_OECD_Consultation_on_an_Update_of_the_Guideli.aspx (consultado el 1o. de octubre de 2019). 
papel más activo a la hora de hacer frente al cambio climático. Por tanto, en el marco de las Líneas Directrices, se espera que las empresas implementen la diligencia debida para abordar los impactos climáticos de sus actividades, productos y servicios, así como de sus cadenas de suministro. ${ }^{96}$

El capítulo de divulgación de información de las Líneas Directrices recomienda que las empresas garanticen la publicación, en los plazos oportunos, de información exacta sobre todos los aspectos significativos de sus actividades, estructura, situación financiera, resultados, accionistas y sistema de gobierno corporativo. Con relación a este tema, analizado en párrafos anteriores, las Líneas Directrices promueven la práctica de divulgar información sobre las emisiones de GEI en la medida en que el campo de aplicación de su seguimiento se extiende a las emisiones directas e indirectas, actuales y futuras, por empresa y por producto. Se recomienda que la información se extienda a las actividades de los subcontratistas y proveedores, o bien de socios empresariales o de joint ventures, con el fin de controlar la transferencia de las actividades perjudiciales para el medio ambiente a otros socios. Según las Líneas Directrices, la divulgación de información sobre temas que van más allá de los resultados financieros constituye un buen medio para manifestar su compromiso con las prácticas socialmente aceptables. Con relación al tema del presente artículo, la divulgación de información sobre las emisiones de GEI puede considerarse un cierto compromiso de las empresas en la lucha contra el cambio climático.

Por otra parte, en el capítulo sobre medio ambiente, las Líneas Directrices recomiendan a las empresas la mejora constante de los resultados ambientales de sus actividades y, cuando corresponda, de su cadena de suministro. Por tanto, promueven el desarrollo y el suministro de productos y servicios que reduzcan las emisiones de GEI. Esto supone que antes de contratar el suministro de productos y servicios, deben evaluar sus emisiones, para que el criterio de selección no recaiga únicamente en la reducción de los costes del servicio. Asimismo, fomentan una mayor conciencia ambiental entre los consumidores, ya que las empresas deben sensibilizar a los clientes sobre las implicaciones ambientales del uso de sus produc-

96 Nieuwenkamp, Roel, "Two Secrets Concerning a Value chain Approach to Corporate Climate Change Risk-Management”, OECD Insights. Debate theissues, 29 de noviembre 2015, disponible en: http://oecdinsights.org/2015/11/29/two-secrets-concerning-a-value-chain-approach-to-corporate-climate-change-risk-management/ (consultado el 1o. de octubre de 2019). 
tos y servicios, informando de manera exacta sobre las emisiones de GEI, entre otras implicaciones ambientales. Finalmente, las Líneas Directrices sugieren la elaboración de estrategias de reducción de las emisiones como medios para mejorar los resultados ambientales a largo plazo. Por tanto, en el marco de las Líneas Directrices, las empresas deben elaborar estrategias que contengan medidas diligentes para reducir sus impactos climáticos, incluidos aquellos que se producen en sus cadenas de suministro.

Las recomendaciones en materia de cambio climático también han sido contempladas en algunas de las guías sectoriales de diligencia debida publicadas por la OCDE, por ejemplo, en la Guía OCDE-FAO para las cadenas de suministro responsable en el sector agrícola. Entre los objetivos de esta Guía se encuentra el aumento de la resiliencia de los sistemas de agricultura y alimentación, los hábitats de soporte y las estrategias de vida dirigidas a la reducción de los efectos del cambio climático a través de medidas de adaptación. ${ }^{97}$ La Guía está dirigida a todas las empresas que operan a lo largo de las cadenas de suministro, incluyendo nacionales y extranjeras, privadas y públicas, pequeñas, medianas y de gran escala, con el objetivo de que cumplan estándares de conducta empresarial responsable. Este documento reconoce que las actividades agrícolas pueden generar impactos externos, incluyendo emisiones de GEI y, por tanto, deben adoptar medidas, conforme resulte adecuado, para reducir o prevenir estas emisiones, con el fin de mejorar su comportamiento ambiental. ${ }^{98}$

No se puede obviar que las recomendaciones de las Líneas Directrices en materia de cambio climático son vagas y generales, ya que no contemplan objetivos específicos de reducción de emisiones de GEI, que podrían contribuir a alcanzar los objetivos del Acuerdo de París. Sin embargo, cabe destacar algunas cuestiones positivas, por ejemplo, que ejercen presión sobre las empresas para que adopten medidas para prevenir que sus operaciones y productos sigan contribuyendo al cambio climático y a sus impactos negativos. Por un lado, a pesar de que las Líneas Directrices son un instrumento no vinculante, su voluntariedad es relativa. En este sentido, Cantú Rivera explica que, dado que las empresas tienen la principal motivación de generar beneficios económicos, el impacto al que su reputación podría

97 Véase, OCDE, Guía OCDE-FAO para las cadenas de suministro responsable en el sector agrícola, París, OCDE, 2017.

98 Ibidem, p. 66. 
estar sujeta con motivo de una conducta irresponsable en el ámbito de los derechos humanos o de la protección del medio ambiente es un aliciente suficientemente poderoso como para alinear su comportamiento con los estándares de conducta empresarial responsable contemplados en las Líneas Directrices. En este sentido, las empresas tienen un interés específico de evitar situaciones en las que tanto ellas como terceros sufran consecuencias negativas (lose-lose situations). Por tanto, el hecho de que las Líneas Directrices no sean legalmente obligatorias no implica que tengan un carácter meramente voluntario. ${ }^{99}$

Por otra parte, a diferencia de otros instrumentos de soft law que promueven la responsabilidad de las empresas de respetar los derechos humanos, las Líneas Directrices contemplan un mecanismo de seguimiento e implementación. Los países adherentes a este instrumento deben establecer Puntos Nacionales de Contacto (PNC) competentes no sólo para promover e implementar las Líneas Directrices, sino para conocer de instancias específicas planteadas por el sector empresarial, las organizaciones de trabajadores, las organizaciones de la sociedad civil y otras partes interesadas en relación con el supuesto incumplimiento de las disposiciones de dicho instrumento por parte de una empresa. ${ }^{100}$

Existen precedentes en los PNC en los que se alegan incumplimientos a las disposiciones en materia de cambio climático. En 2007, por ejemplo, se interpuso una instancia específica ante el PNC de Alemania en contra de la empresa Volkswagen, alegando que la empresa no estaba divulgando información sobre las emisiones de GEI de sus vehículos y llevaba a cabo una campaña en contra de la normativa climática. ${ }^{101}$ En 2009, un segundo caso ante el PNC de Alemania se presentó en contra de la empresa Vattenfall por los potenciales impactos de las emisiones de GEI de una central térmica

99 Cantú Rivera, Humberto, "La OCDE y los derechos humanos: el caso de las Directrices para Empresas Multinacionales y los Puntos de Contacto Nacional”, Anuario Mexicano de Derecho Internacional, México, 2015, vol. 15, núm. 1, pp. 611-658.

100 Para un análisis sobre la aplicación de las Líneas Directrices y de sus PNC para regular el comportamiento de las empresas y prevenir abusos de derechos humano y daños ambientales, véase, Robinson, Scott, "International Obligations, State Responsibility and Judicial Review Under the OECD Guidelines for Multinational Enterprises Regime”, Utrecht Journal of International and European Law, 2014, vol. 30, núm. 78, pp. 79 y 80.

101 Véase, Germanwatch vs. Volkswagen, disponible en: www.oecdwatch.org/cases/Case_119 (consultado el 1o. de octubre de 2019). 
de carbón, lo que incumplía las recomendaciones de las Líneas Directrices sobre políticas ambientales nacionales y protección del consumidor. ${ }^{102} \mathrm{Un}$ tercer caso se presentó en el PNC de Noruega en contra de la empresa estatal Statoil por su complicidad con Canadá en el incumplimiento de las obligaciones internacionales de reducir sus emisiones de GEI. En este caso se alegó que las inversiones de la empresa en actividades de extracción de arenas bituminosas (oilsands) eran contrarias a lo estipulado en el capítulo sobre medio ambiente de las Líneas Directrices. ${ }^{103}$ No obstante, todas estas instancias específicas relacionadas con el cambio climático fueron desestimadas, ya sea porque las cuestiones alegadas no estaban dentro de las competencias de los PNC, o bien, por la falta de fundamentos en las quejas.

En 2017, diversas ONG, incluidas OxfamNovib, Greenpeace, BankTracky Friends of the Earth Netherlands, interpusieron una queja ante el PNC de los Países Bajos, alegando que ING Bank violaba las disposiciones climáticas de las Líneas Directrices. Según las ONG, este banco no evaluaba los impactos climáticos de sus actividades financieras, ni divulgaba información sobre las emisiones de GEI de dichas actividades. Por tanto, se solicitaba al PNC que el banco identificara y publicara las emisiones de GEI directas e indirectas que producían los proyectos y empresas que recibían financiamiento por parte del banco. Este es el primer precedente en que un PNC acepta un caso relacionado con las disposiciones en materia de cambio climático, señalando expresamente que "[u]ndertheterms of the OECD Guidelines companies are expected to conduct a duediligence process in respect of their environmental impact, including climate impact". ${ }^{104}$ En abril de 2019, el PNC publicó el informe final del proceso de instancia específica en el que destacó que la observancia de las Líneas Directrices implica que las em-

102 Idem.

103 Norwegian Climate Network et al v. Statoil, disponible en: www.oecdwatch.org/cases/ Case_248 (consultado el 1o. de octubre de 2019).

104 Véase, Dutch Ministry of Foreign Affairs-OECD National Contact Point, "Initial Assessment. Notification Oxfam Novib, Greenpeace, BankTrack, Friends of the Earth Netherlands (Milieudefensie) vs. ING", 14 de noviembre de 2017, disponible en: www.oecdguidelines. nl/documents / publication/2017/11/14/publication-dutch-ncp-initial-assessment-filed-by-4-ngosvs.-ing-bank (consultado el 1o. de octubre de 2019). Para una descripción de los hechos, véase, Chiaro, Elisa, “Corporate Responsibility for Climate Change: Litigation and Other Grievance Mechanisms”, Doing Business Right Blog, 30 de enero de 2018, disponible en: www. asser.nl / DoingBusinessRight / Blog/post/corporate-responsibility-for-climate-change-litigation-andother-grievance-mechanisms-by-elisa-chiaro\#_ftnref35 (consultado el 1o. de octubre de 2019). 
presas deben establecer objetivos concretos para gestionar sus impactos de conformidad con las políticas nacionales y los compromisos internacionales en materia de medio ambiente. Por tanto, sugirió a ING Bank que formulara objetivos concretos de reducción de emisiones para sus servicios financieros que estuvieran alineados con el Acuerdo de París. ${ }^{105}$

\section{Los Principios sobre Obligaciones Climáticas de las Empresas}

Finalmente, cabe hacer referencia a los Principios sobre Obligaciones Climáticas de las Empresas (Enterprises Principles) de 2018, ${ }^{106}$ que dan seguimiento a los Principios de Oslo sobre Obligaciones Globales respecto al Cambio Climático. ${ }^{107}$ Los Principios de Oslo fueron adoptados en 2015 por un grupo de expertos compuesto por académicos, jueces y abogados de prestigio internacional de diferentes países, como Brasil, China, India, Estados Unidos y Países Bajos. Estos Principios articulan y clarifican las obligaciones de los Estados y, en menor medida, de las empresas, de adoptar medidas urgentes para minimizar los efectos catastróficos del cambio climático.

Los Principios de Oslo se rigen por una interpretación del principio de precaución contenido en el principio 15 de la Declaración de Río sobre el Medio Ambiente y el Desarrollo. Por ello, señalan que, teniendo en cuenta la evidencia clara y contundente de que los GEI producidos por la actividad humana están causando cambios significativos en el clima y que éstos implican un riesgo grave de daños irreversibles a la humanidad, incluyendo a las actuales y futuras generaciones, se requiere que se reduzcan las emisiones globales de GEI. Esta reducción se debe hacer en la dimensión y al ritmo necesario para procurar la protección frente a las amenazas y riesgos del cambio climático. Para lograr el objetivo de reducción de los niveles

105 Véase, "NCP Final Statement notification 4 NGOs vs. ING", disponible en: www.oecdguidelines.nl/documents / publication/2019/04/19/ncp-final-statement-4-ngos-vs-ing (consultado el 1o. de octubre de 2019).

106 Expert Groupon Climate Obligations of Enterprises, Principles on Climate Obligations of Enterprises, La Haya, Eleven International Publishing, 2018.

107 Sobre los Principios de Oslo y sus comentarios, véase, ExpertGroupon Global Climate Obligations, Oslo Principles on Global Climate Obligations, La Haya, Eleven International Publishing, 2015. 
de GEI requeridos, debería estar basado en los peores escenarios, creíbles y realistas. Todas las medidas adoptadas en cumplimiento del principio de precaución deberían ser llevadas a cabo sin considerar los costos, excepto cuando éstos sean completamente desproporcionados con relación a las reducciones logradas. ${ }^{108}$ Para ello, se propone la elaboración de un plan de reducción de emisiones continuo que garantice que el total del aumento de la temperatura media de la superficie terrestre nunca exceda las temperaturas preindustriales en más de $2^{\circ} \mathrm{C} .{ }^{109}$

Según Spier, uno de los miembros del grupo de expertos, durante el proceso de elaboración de los Principios de Oslo, fue relativamente fácil llegar a un acuerdo sobre las obligaciones climáticas de los Estados, pero no lo fue para el caso de las empresas. ${ }^{110}$ A pesar de ello, el documento final de los Principios de Oslo incluyó cuatro obligaciones dirigidas a las empresas y a las entidades bancarias y financieras, que son complementarias a las de los Estados (principios 27-30). En el marco de los Principios de Oslo, las empresas deberían evaluar la vulnerabilidad y el efecto financiero que el cambio climático tendrá sobre sus actividades, así como llevar a cabo un análisis de la huella de carbono antes de construir cualquier nueva instalación. Por su parte, las entidades bancarias y financieras deben tener en cuenta los efectos de las emisiones de GEI de cualquier proyecto que vayan a financiar.

Por lo anterior, un grupo de expertos consideró pertinente profundizar en las obligaciones climáticas de las empresas e inversores para complementar los Principios de Oslo y conseguir el objetivo establecido en el Acuerdo de París. ${ }^{111}$ Este grupo de expertos partió de dos consideraciones básicas para la elaboración de dicho documento, que clarifica las obligaciones de las

108 Borràs Pentinat, Susana y Felipe Pérez, Beatriz, "El régimen jurídico del cambio climático: entre la justicia climática y los derechos humanos", Working Paper No. 2, disponible en: www.dret-public.urv.cat/media/upload/domain_89/arxius/working\%20papers/DEFINITIUS / working\%20paper\%202.pdf (consultado el 1o de octubre de 2019).

109 Nagra, Satvindar, "The Oslo Principles and Climate Change Displacement: Missed Opportunity or Misplaced Expectations?”, Carbon \& Climate Law Review, vol. 11, núm. 2, 2017, pp. 120-135.

110 Spier, Jaap, “The Oslo Principles and the Enterprises Principles: Legal Strategies to Come to Grips with Climate Change”, Journal of European Tort Law, vol. 8, núm. 2, 2017, pp. 218-237.

111 El grupo de expertos de los Enterprises Principles está conformado por juristas reconocidos de diferentes partes del mundo: Thomas Pogge, Brian Preston, Tianbao Qin, James Silk, Jaap Spier (reporter), Elisabeth Steiner, Philip Sutherland y Daniël Witte. 
empresas (públicas y privadas) frente al cambio climático. En primer lugar, las empresas, junto con otros actores, contribuyen a generar un peligro inminente si no reducen de manera significativa sus emisiones de GEI. Es decir, si las empresas continúan con el paradigma del business as usual crean un riesgo inaceptable que puede evitarse a un costo relativamente modesto. En segundo lugar, si las empresas no reducen sus emisiones, los Estados no pueden alcanzar sus objetivos de reducción establecidos en sus compromisos internacionales. ${ }^{112}$

Los Enterprises Principles articulan 30 principios no vinculantes, acompañados de sus respectivos comentarios, que detallan una serie de medidas enfocadas principalmente en la mitigación del cambio climático, a través de la reducción y prevención de emisiones de GEI, las cuales deben alinearse con los compromisos internacionales de los Estados. Asimismo, incluyen medidas relacionadas con los productos y servicios de las empresas y sus cadenas de suministro. Estos principios no crean nuevas obligaciones para las empresas ni remplazan instrumentos en vigor, sino más bien consisten en una interpretación de la legislación en el estado actual combinada con una predicción de los posibles desarrollos legales en materia de cambio climático en un futuro próximo. ${ }^{113}$ Por tanto, los Enterprises Principles emanan de diversas áreas del derecho positivo: privado, ambiental, derechos humanos, corporativo, así como de instrumentos soft law, como códigos de conducta y de buen gobierno corporativo, sentencias de tribunales internacionales y nacionales, informes y doctrina legal.

Las obligaciones de reducción contempladas en el principio 2o. constituyen la piedra angular de los Enterprises Principles. Bajo el enfoque preventivo de este instrumento, se pone énfasis en la reducción de emisiones de GEI de las actividades empresariales para mantener el aumento de la temperatura media mundial muy por debajo de $2^{\circ} \mathrm{C}$ con respecto a los niveles preindustriales. Las obligaciones de reducción no sólo aplican directamente a las

112 Sobre este punto, Spier señala que "[a]fter all, as a rule of thumb, states will only be able to meet their reduction obligations if enterprises under their jurisdiction reduce their emissions at the same rate." Spier, Jaap, "Legal Obligations of Enterprises and Investors in the Face of Climate Change", Chinese Journal of Environmental Law, 2018, vol. 2, núm. 1, pp. 99-111.

113 Véase el análisis de los Principios sobre Obligaciones Climáticas de las Empresas en Spier, Jaap, "The Principles on Climate Obligations of Enterprises: An Attempt to Give Teeth to the Universally Adopted View that We Must Keep Global Warming below an Increase of Two Degrees Celsius”, Uniform Law Review, vol. 23, núm. 2, 2018, pp. 1-17. 
actividades de una determinada empresa, sino que también garantizan que cualquier otra entidad que esté bajo su control cumpla con las obligaciones de reducir emisiones de GEI (principio 6). Asimismo, estas obligaciones se relacionan directamente con los objetivos y compromisos internacionales de los Estados en los que operan las empresas. Esta flexibilidad puede crear divergencias importantes en las obligaciones de reducción, lo que sigue favoreciendo que las empresas elijan estratégicamente el lugar de sus operaciones, alejándose así de aquellos Estados con compromisos climáticos más estrictos. No obstante, el principio 15 establece que las empresas deben cumplir con las obligaciones de los Enterprises Principles, incluso si las leyes nacionales o los acuerdos internacionales, vigentes o adoptados posteriormente, requieren una reducción menos estricta de las emisiones de GEI.

Los Enterprises Principles se aplican a todas las empresas, sin embargo, hacen especial énfasis en las globales, entendidas como las empresas, o grupo de empresas, que generan productos u ofrecen servicios en diversos Estados a través de subsidiarias. En el marco de los Enterprises Principles, las empresas globales tienen mayores obligaciones de reducción de emisiones en sus operaciones transnacionales, dado que son actores globales con la capacidad de deslocalizar sus actividades a Estados con compromisos climáticos más laxos, así como, por su gran influencia económica y política para poder mejorar la acción climática global. ${ }^{114}$ Este tratamiento diferenciado se alinea con el régimen internacional del cambio climático, que se ha regido por el principio de las responsabilidades comunes pero diferenciadas. El artículo 3o. de la CMNUCC determina, de conformidad con el Principio 7o. de la Declaración de Río de 1992, que los Estados parte deben proteger el sistema climático. Sin embargo, impone mayores obligaciones a los países industrializados que, a lo largo de la historia han aumentado exponencialmente el calentamiento global debido a su sistema de consumo y producción, basado en la quema de combustibles fósiles y en prácticas industriales sumamente contaminantes. ${ }^{115}$ Por tanto, teniendo en cuenta su deuda histórica y su capacidad económica y técnica, las empresas de los Carbon Majors adquieren un deber de tomar la iniciativa en lo que respecta a

114 Expert Group on Climate Obligations of Enterprises, op. cit., pp. 129 y130.

115 Arístegui, Juan Pablo, "Evolución del principio «responsabilidades comunes pero diferenciadas» en el régimen internacional del cambio climático”, Anuario de Derecho Público UDP, núm.1, 2012, pp. 585-611. 
combatir el cambio climático y sus efectos adversos. Mientras tanto, las pequeñas y medianas empresas también deben contribuir a alcanzar el objetivo establecido en el Acuerdo de París, a través de obligaciones más flexibles que correspondan con sus contribuciones al cambio climático y atendiendo a sus capacidades y recursos.

El abanico de medidas y acciones de reducción de emisiones de GEI contempladas en los Enterprises Principles es amplio y son lo suficientemente generales, pero precisas a la vez como para indicar qué se espera de las empresas. El principio 7o. enumera una serie de medidas, sin costes adicionales, que deben aplicar para reducir sus emisiones de GEI y mejorar su eficiencia energética. Por ejemplo, apagar los equipos que consumen energía cuando no están en uso, eliminar el consumo excesivo de energía en calefacción, refrigeración e iluminación, evitar el consumo innecesario de los dispositivos al proporcionar una función de apagado automático o aumentar la vida útil de los productos. Por su parte, el principio 8o. señala que deben tomar medidas para reducir las emisiones de GEI de sus actividades que incurren en costos adicionales si éstos se compensan con ahorros financieros futuros o ganancias financieras dentro de un periodo razonable.

Por otra parte, los Enterprises Principles establecen que las empresas que lleven a cabo actividades, productos y servicios que generen o puedan generar emisiones excesivas de GEI, deben adoptar medidas compensatorias por dichas emisiones. Por tanto, las operaciones de las centrales eléctricas de carbón, la extracción de petróleo y el fracking, actividades que en principio generan emisiones de GEI de manera excesiva, deben evitarse a menos que se contemplen medidas para compensar el exceso de emisiones de GEI. En este sentido, también se considera que son desproporcionadas las emisiones de una empresa si son superiores a las de sus competidores. En relación con los productos y servicios que generan emisiones excesivas de GEI, las empresas no sólo deben adoptar las medidas compensatorias, sino que deben plantearse su rediseño (principios 9o. y 10).

A pesar de que las emisiones de las actividades de una empresa sean mínimas o ésta haya cumplido con sus obligaciones de reducción, no la exime de cumplir con otras obligaciones contempladas en los Enterprises Principles (principio 14). En estos casos, debe evaluar las emisiones de GEI de sus proveedores de bienes y servicios al momento de seleccionarlos (principio 17). Asimismo, debe evaluar y divulgar información de manera continua sobre los impactos climáticos a los que contribuyen sus actividades, pro- 
ductos y servicios (principio 21), así como sobre los riesgos a los que está expuesta, los efectos financieros que produce el cambio climático sobre sus actividades y el coste de las medidas técnicas y financieras de reducción de emisiones (principio 18). Esta información debe estar disponible y accesible en la página web para las partes afectadas, directa e indirectamente, por las actividades de la empresa, incluidos inversores, accionistas, clientes, empleados, reguladores de valores y el público en general (principio 20). De hecho, las obligaciones de divulgar información de los Enterprises Principles están inspiradas en la diligencia debida contemplada en los Principios Rectores. Parte del proceso consiste en comunicar a las partes interesadas los impactos de las actividades de las empresas y las medidas adoptadas para hacer frente a dichos impactos. ${ }^{116}$

Finalmente, los Enterprises Principles promueven que las empresas realicen una evaluación de impacto ambiental antes de construir cualquier instalación nueva o ampliar una instalación existente. Dicha evaluación debe realizarse de conformidad con las mejores prácticas existentes y debe incluir la huella de carbono de la instalación propuesta, los efectos climáticos, las formas de reducirlos y las consecuencias que el cambio climático puede tener en la instalación propuesta (principio 24). En este sentido, en el ámbito europeo, la Directiva 2011/92/UE relativa a la evaluación de las repercusiones de determinados proyectos públicos y privados sobre el medio ambiente determina que los Estados miembros de la UE adoptarán las medidas necesarias para que el promotor de un proyecto suministre información sobre los elementos del medio ambiente que se puedan ver afectados de forma considerable por el proyecto propuesto, incluidos los factores climáticos. ${ }^{117}$

Los Enterprises Principles están sujetos a mejoras, sin lugar a duda. Por ejemplo, se les podría atribuir un mayor enfoque de derechos humanos, alineado con la orientación del Acuerdo de París. Por otra parte, las obligaciones de reparación de daños por los impactos climáticos asociados a las actividades de las empresas merecen un espacio en este instrumento,

116 Expert Group on Climate Obligations of Enterprises, op. cit., p. 185.

117 Véase, Anexo IV de la Directiva 2011/92/UE del Parlamento Europeo y del Consejo, del 13 de diciembre de 2011, relativa a la evaluación de las repercusiones de determinados proyectos públicos y privados sobre el medio ambiente, DO L 26, de 28 de enero de 2012, p. 1/21, disponible en: https: / / eur-lex.europa.eu/legal-content/ES/TXT/HTML/?uri=CELEX:3 2011 L0092\&from=ES (consultado el 01/10/19). 
en caso de que no se cumplan las obligaciones de reducción de emisiones de GEI. Asimismo, aunque no sea un instrumento sujeto a la firma y ratificación de los Estados, requiere de un respaldo por parte de los mismos para una mayor legitimación y sobre todo para que las empresas incorporen sus principios en sus operaciones. No obstante, a pesar de estos puntos mejorables, los Enterprises Principles constituyen un instrumento innovador, orientador y único en su clase que contribuye a cubrir los vacíos del régimen internacional del cambio climático respecto a las obligaciones directas de las empresas en la lucha contra este fenómeno de dimensiones globales. Sin embargo, la materialización de los principios en la práctica, por parte de las empresas, se constituye como el principal obstáculo a superar. Como bien indica Spier, a raíz de las consultas con empresarios y entidades financieras, "there was not much appetite in the business community for the idea that enterprises have legal obligations in the face of climate change. Most discussion partners preferred non-binding rules and voluntary pledges". ${ }^{118}$

\section{CONCLUSIONES}

No cabe duda que el cambio climático es una amenaza para la comunidad internacional que requiere de acciones urgentes para evitar el colapso de nuestra especie, así como la extinción del resto. Se trata de uno de los principales desafíos del derecho internacional contemporáneo, que requiere que los Estados, en el ejercicio de su soberanía, reformulen sus sistemas económicos y promuevan una transición energética justa y efectiva. Sin embargo, en los instrumentos internacionales, en materia de cambio climático, persisten importantes lagunas normativas para abordar de manera efectiva la lucha contra este problema global y contrarrestar sus efectos negativos. El régimen internacional del cambio climático, en su estado actual, se ve sobrepasado por el modelo económico global, que continúa dependiendo de la quema de combustibles fósiles. Esto permite que los agentes económicos, como las empresas, sigan obteniendo grandes beneficios a costa de la crisis climática, con base en la especulación del aumento de la demanda energética.

118 Spier, Jaap, “The Principles on Climate Obligations...”, cit., p. 15. 
La contribución de las empresas a la crisis climática no es baladí, como tampoco lo son sus intentos de obstaculizar o de influir en las negociaciones y políticas climáticas globales en beneficio propio. El actual régimen internacional del cambio climático descentraliza la gobernanza climática global, lo que atribuye a las empresas un papel más activo. No obstante, se mantiene dentro de los límites del statu quo del derecho internacional, por lo que el objetivo de mantener el aumento de la temperatura mundial por debajo de $2{ }^{\circ} \mathrm{C}$ con respecto a los niveles preindustriales sigue dependiendo en mayor medida de la voluntad política de los Estados, con diferentes capacidades, recursos, culturas y grados de compromisos con la protección del medio ambiente y sus elementos.

Mientras tanto, las acciones climáticas de las empresas, muchas de ellas con mayores capacidades y recursos que algunos Estados, orbitan en el ámbito de la voluntariedad. Estas acciones responden principalmente a la presión de agentes externos (ONG, consumidores, competidores) y a las condiciones del mercado. Este sistema se muestra sobradamente inefectivo para alcanzar los objetivos del Acuerdo de París, y para influir en el modelo y prácticas corporativas de las empresas. Por ello, la presente investigación propone la aplicación horizontal de los instrumentos internacionales en materia de cambio climático, con el fin de imponer a las empresas mayores obligaciones de reducción de emisiones y de promoción de una transición energética. La evolución hacia un régimen internacional de responsabilidad mutua que imponga a los Estados y empresas compromisos vinculantes de reducción podría ser clave para evitar el fracaso que lleve al colapso del sistema climático. En este sentido, el Acuerdo de París aporta una fórmula novedosa al derecho internacional contemporáneo que se podría ajustar a las actividades de las empresas. Un mecanismo voluntario de compromisos determinados similar al de los Estados podría ser viable para algunas empresas o sectores industriales, que contribuyen de manera significativa al cambio climático. Así, se les impondría una obligación flexible de reducir emisiones teniendo en cuenta sus intereses y circunstancias específicas.

El consenso global con relación a la responsabilidad de las empresas de respetar los derechos humanos reconocidos en los instrumentos internacionales supone importantes oportunidades para exigirles que contribuyan a alcanzar los objetivos del Acuerdo de París. No sólo a través de la imposición directa de obligaciones de reducción de emisiones, sino también de obligaciones de diligencia debida para que establezcan un proceso continuo 
que permita identificar, prevenir, mitigar y responder por las contribuciones al cambio climático de sus actividades, productos y servicios, así como de sus cadenas de suministro. Si las empresas no contribuyen a asegurar la estabilidad del sistema climático, sus acciones y compromisos con el respeto de los derechos humanos carecen de un fin. En este sentido, cabe destacar los avances en algunos instrumentos internacionales soft law que promueven la responsabilidad de respetar los derechos humanos y añaden un valor agregado a la gobernanza climática global, ya que incorporan estándares climáticos aplicables a las actividades y relaciones comerciales de las empresas. Estos instrumentos, analizados en el presente artículo, sirven de modelo para articular obligaciones directas y claras para estas entidades en virtud del régimen internacional del cambio climático.

El debilitamiento del Estado en el contexto de la globalización plantea serias dudas sobre su capacidad y voluntad política para hacer frente a la crisis social y ambiental en la era del Antropoceno. Por tanto, es necesaria una reconceptualización de las nociones básicas y los esquemas obsoletos del orden legal internacional que permita ampliar el umbral de sujetos reconocidos en virtud del derecho internacional. El cambio climático pone en evidencia la necesidad de seguir explorando las fronteras del derecho internacional respecto a las obligaciones y responsabilidades de las empresas. Estos actores globales son entidades clave en la aplicación del régimen internacional del cambio climático y sus acciones son determinantes para alcanzar los objetivos planteados en el Acuerdo de París.

\section{BiBLIOGRAFíA ${ }^{119}$}

ÁlVAREZ, José E., “Are Corporations Subjects of International Law?”, Santa Clara Journal of International Law, vol. 9, núm. 1, 2011.

Amis, L., A Guide for Business: How to Develop a Human Rights Policy, United Nations Global Compact Office-Office of the United Nations High Commissioner for Human Rights, 2011.

119 En lo que respecta a las fuentes distintas de la literatura legal, por ejemplo, jurisprudencia o informes de organismos gubernamentales y no gubernamentales, véase notas a pie de página. 
Esta revista forma parte del acervo de la Biblioteca Jurídica Virtual del Instituto de Investigaciones Jurídicas de la UNAM

ARATO, Julian, “Corporations as Lawmakers”, Harvard International Law Journal, vol. 56, núm. 2, 2015.

ARÍsTEGUI, Juan Pablo, “Evolución del principio «responsabilidades comunes pero diferenciadas» en el régimen internacional del cambio climático", Anuario de Derecho Público UDP, núm.1, 2012.

BÄCKSTRAND, Karin et al., "Non-State Actors in Global Climate Governance: from Copenhagen to Paris and beyond", Environmental Politics, vol. 26, no. 4, 2017.

Borràs PENTINAT, Susana y FELIPE PÉREZ, Beatriz, "El régimen jurídico del cambio climático: Entre la justicia climática y los derechos humanos", Working Paper, no. 2.

Boyle, Alan, "Climate Change, The Paris Agreement and Human Rights", International and Comparative Law Quarterly, vol. 67, no. 4, 2018.

CAntú Rivera, Humberto, "La OCDE y los derechos humanos: el caso de las Directrices para Empresas Multinacionales y los Puntos de Contacto Nacional”, Anuario Mexicano de Derecho Internacional, vol. 15, núm. 1, 2015.

ČERNIČ, JernejLetnar, “The 2011 Update of the OECD Guidelines for Multinational Enterprises”, American Society of International Law Insights, vol. 16, no. 4, 2012.

Corporate Accountability International et al., How Big Polluters are Undermining Global Climate Policy, Johanesburgo-Bruselas-Boston-Davo City, Corporate Accountability International, ActionAid, APMDD, CEO, ETC Group, 2017.

Corporate Accountability International, Inside Job: Big Polluters' Lobbyists on the inside at the UNFCCC, Londres, Corporate Accountability International, 2017.

Dellinger, Myanna, "See You in Court: Around the World in Eight Climate Change Lawsuits", William \& Mary Environmental Law and Policy Review, vol. 42, núm. 2, 2018.

Deva, Surya, "Taking Nature Seriously Can the UN Guiding Principles Tame Corporate Proiteering?", en VolgT, Christina (ed.), Rule of Law for Nature. New Dimensions and Ideas in Environmental Law, Cambridge, CUP, 2013.

Deva, Surya, “Treating Human Rights Lightly: A Critique of the Consensus Rhetoric and the Language Employed by the Guiding Principles", en Deva, Surya y BILCHITZ, David (eds.), Human Rights Obligations of Business Beyond the Corporate Responsibility to Respect?, Cambridge, CUP, 2013. 
Esta revista forma parte del acervo de la Biblioteca Jurídica Virtual del Instituto de Investigaciones Jurídicas de la UNAM

EKwURZEL, Brenda et al., "The Rise in Global Atmospheric $\mathrm{CO}_{2}$, Surface Temperature, and Sea Level from Emissions Traced to Major Carbon Producers", Climatic Change, vol. 144, núm. 4, 2017.

EXPerT Group on Climate Obligations of enterprises, Principles on Climate Obligations of Enterprises, La Haya, Eleven International Publishing, 2018.

Expert Group on Global Climate Obligations, Oslo Principles on Global Climate Obligations, La Haya, Eleven International Publishing, 2015.

FajARdo, Teresa, "El Acuerdo de París sobre el cambio climático: sus aportaciones al desarrollo progresivo del derecho internacional y las consecuencias de la retirada de los Estados Unidos”, Revista Española de Derecho Internacional, vol. 70, núm. 1, 2018.

FERREY, Steven, "Corporate social responsibility and climate change", en Farber, Daniel A. y PeEters, Marjan (eds.), Climate Change Law, vol I, Cheltenham-Massachussetts, Edwar Elgar, 2016.

GARCÍA-ÁLvArEZ, Laura, "El caso Huaraz: David contra Goliat o «Saúl L. contra RWE AG»: Un precedente clave en la justicia climática”, Revista Aranzadi de Derecho Ambiental, núm. 40, 2018.

Global Reporting Initiative (GRI), CSR Europe, AcCountancy EUROPE, Member State Implementation of Directive 2014/95 / EU. A comprehensive overview of how Member States are implementing the EU Directive on Non-financial and Diversity Information, Bruselas-Ámsterdam, GRI-CRS Europe, 2017.

GRIFFIn, Paul, The Carbon Majors Database. CDP Carbon Majors Report 2017, Londres, CPD UK, 2017.

HeEDE, Richard, "Tracing Anthropogenic Carbon Dioxide and Methane Emissions to Fossil Fuel and Cement Producers, 1854-2010", Climatic Change, vol. 122, núm. 1-2, 2013.

InTERnational BAR AsSOCIATION (IBA), Achieving Justice and Human Rights in an Era of Climate Disruption, Londres, IBA, 2014.

Iglesias MÁrqueZ, Daniel y FeliPe PÉreZ, Beatriz, "Anhelando justicia en la era del cambio climático: de la teoría a la práctica”, Revista Catalana de Derecho Ambiental, vol. 9, núm. 2, 2018.

IGLESIAS MÁRQUEZ, Daniel, "Explorando las fronteras del derecho internacional de los derechos humanos: hacia la adopción de un tratado internacional sobre empresas y derechos humanos", Akademía. Revista Internacional y Comparada de Derechos Humanos, vol. 1, núm. 1, 2018. 
Esta revista forma parte del acervo de la Biblioteca Jurídica Virtual del Instituto de Investigaciones Jurídicas de la UNAM

IGLESIAS MÁrQUEZ, Daniel, "La litigación climática en contra de los Carbon Majors en los Estados de origen: apuntes desde la perspectiva de empresas y derechos humanos”, Revista Electrónica de Estudios Internacionales, núm. 37, 2019.

IGLESIAS MÁRQUEZ, Daniel, "La responsabilidad de las empresas de respetar los derechos humanos en el contexto de la crisis climática”, Revista de Direito Internacional, 2019 (en prensa).

IGLESIAS MÁRQUEZ, Daniel, La regulación de las empresas transnacionales domiciliadas en la Unión Europea en relación con sus estándares de comportamiento y su responsabilidad por los daños ambientales causados en terceros Estados, tesis doctoral, Universitat Rovira i Virgili, 2017.

InfluenCE MAP, Big Oil's Real Agenda on Climate Change, Londres, Influence Map, 2019.

IPCC, "Summary for Policymakers", en IPCC, Global warming of $1.5^{\circ} \mathrm{C}$. An IPCC Special Report on the impacts of global warming of $1.5^{\circ} \mathrm{C}$ above pre-industrial levels and related global greenhouse gas emission pathways, in the context of strengthening the global response to the threat of climate change, sustainable development, and efforts to eradicate poverty, Ginebra, World Meteorological Organization, 2018.

IPCC, Climate Change 2007: Mitigation. Contribution of Working Group III to the Fourth Assessment Report of the Intergovernmental Panel on Climate Change, Cambridge/Nueva York, Cambridge University Press, 2007.

JOACHIM, Karl, “The OECD Guidelines for Multinational Enterprises”, en AdDo, M. K. (ed.), Human Rights Standards and the Responsibility of Transnational Corporations, La Haya, Kluwer Law International, 1999.

LÖVBrand, Eva et al., "Making Climate Governance Global: how UN climate Summitry comes to Matter in a Complex Climate Regime", Environmental Politics, vol. 26, núm. 4, 2017.

MCCRImmon, Don, "The Athabaskan Petition to the Inter-American Human Rights Commission: Using Human Rights to Respond to Climate Change”, The Polar Journal, vol. 6, núm. 2, 2016.

Murray, Jill, "A New Phase in the Regulation of Multinational Enterprises: the Role of the OECD”, Industrial Law Journal, vol. 30, núm. 3, 2001.

NAGRA, Satvindar, "The Oslo Principles and Climate Change Displacement: Missed Opportunity or Misplaced Expectations?”, Carbon \& Climate Law Review, vol. 11, núm. 2, 2017. 
Esta revista forma parte del acervo de la Biblioteca Jurídica Virtual del Instituto de Investigaciones Jurídicas de la UNAM

NASIRITOUSI, Naghmeh et al., "The Roles of Non-State Actors in Climate Change Governance: Understanding Agency Through Governance Profiles”, International Environmental Agreements: Politics, Law and Economics, vol. 16, núm. 1, 2016.

NASIRITOUSI, Naghmeh, "Fossil Fuel Emitters and Climate Change: Unpacking the Governance Activities of Large Oil and Gas Companies", Environmental Politics, vol. 26, núm. 4, 2017.

Nava Escudero, César, "El Acuerdo de París. Predominio del Soft Law en el Régimen Climático", Boletín Mexicano de Derecho Comparado, vol. 49, núm. 147, 2016.

Nolan, Justine, "Hardening Soft Law: are the Emerging Corporate Social Disclosure Laws Capable of Generating Substantive Compliance with Human Rights?", Revista de Direito Internacional, vol. 15, núm. 2, 2018.

OCDE, Guía OCDE-FAO para las cadenas de suministro responsable en el sector agrícola, París, OCDE, 2017.

OCDE, Líneas Directrices de la OCDE para Empresas Multinacionales, París, OECD Publishing, 2013.

OECD y CDSB, Climate Change Disclosure in G20. Countries Stocktaking of Corporate Reporting Schemes, París-Londres, OECD-CDSB, 2015.

OlawUYI, Damilola S., "Climate Justice and Corporate Responsibility: Taking Human Rights Seriously in Climate Actions and Projects", Journal of Energy \& Natural Resources Law, vol. 34, núm. 1, 2016.

OsOfSKY, Hari M., "The Role of Climate Change Litigation in Establishing the Scale of Energy Regulation", Annals of the Association of American Geographers, 101, núm. 4, 2011.

RobINSON, Scott, "International Obligations, State Responsibility and Judicial Review under the OECD Guidelines for Multinational Enterprises Regime”, Utrecht Journal of International and European Law, vol. 30, núm. 78, 2014.

RodríGuEZ García, Noel, "Responsabilidad del Estado y cambio climático: el caso Urgenda contra Países Bajos”, Revista Catalana de Derecho Ambiental, vol. 7, núm. 2, 2016.

RugGiE, John G., "The Construction of the UN «Protect, Respect and Remedy» Framework for Business and Rights: The True Confessions of a Principled Pragmatist”, European Human Rights Law Review, núm. 2, 2011. Ruggie, John y Nelson, Tamaryn, "Human Rights and the OECD Guidelines for Multinational Enterprises: Normative Innovations and Imple- 
Esta revista forma parte del acervo de la Biblioteca Jurídica Virtual del Instituto de Investigaciones Jurídicas de la UNAM

mentation Challenges", Corporate Social Responsibility Initiative Working Paper No. 66. Cambridge, John F. Kennedy School of Government, Harvard University.

SABIDO, Pascoe, Receta para el cambio climático. La influencia de las empresas responsables de crímenes del clima sobre la COP 21, Bruselas, Corporate Europe Obversatory, 2015.

Salinas AlcegA, Sergio, "El Acuerdo de París de diciembre de 2015: la sustitución del multilateralismo por la multipolaridad en la cooperación climática internacional”, Revista Española de Derecho Internacional, vol. 70, núm. 1, 2018.

SARa L. y SlatTery, Michael, "Business, Human Rights and the IBA Climate Justice Report", Journal of Energy \& Natural Resources Law, vol. 34, núm. 1, 2016.

SPIER, Jaap, "The Oslo Principles and the Enterprises Principles: Legal Strategies to Come to Grips with Climate Change", Journal of European Tort Law, vol. 8, núm. 2, 2017.

SPIER, Jaap, "Legal Obligations of Enterprises and Investors in the Face of Climate Change", Chinese Journal of Environmental Law, vol. 2, núm. 1, 2018.

SPIER, Jaap, "The Principles on Climate Obligations of Enterprises: An Attempt to Give Teeth to the Universally Adopted View that We Must Keep Global Warming below an Increase of Two Degrees Celsius”, Uniform Law Review, vol. 23, núm. 2, 2018.

SCHuTter, Olivier de, “The Challenge of Imposing Human Rights Norms on Corporate Actors", en SCHUTTER, Olivier de (ed.), Transnational Corporations and Human Rights, Oxford, Hart, 2006.

UNEP, Climate Change and Human Rights, Nairobi, UNEP, 2015.

VANASSELT, Harro, "The Role of Non-State Actors in Reviewing Ambition, Implementation, and Compliance under the Paris Agreement", Climate Law, vol. 6, núm. 1-2, 2016.

Verschuuren, Jonathan, "The State of the Netherlands vs. Urgenda Foundation: The Hague Court of Appeal upholds judgment requiring the Netherlands to further reduce its greenhouse gas emissions", Review of European, Comparative and International Environmental Law, vol. 28, núm. $1,2019$. 